\title{
Variations in Summer Extreme High-Temperature Events over Northern Asia and the Possible Mechanisms
}

\author{
HAIXU HONG, ${ }^{\mathrm{a}, \mathrm{b}}$ JIANQI SUN, ${ }^{\mathrm{a}, \mathrm{b}, \mathrm{c}}$ AND HUIJUN WANG ${ }^{\mathrm{c}, \mathrm{a}}$ \\ ${ }^{a}$ Nansen-Zhu International Research Center, Institute of Atmospheric Physics, Chinese Academy of Sciences, Beijing, China \\ ${ }^{\mathrm{b}}$ University of Chinese Academy of Sciences, Beijing, China \\ ${ }^{\mathrm{c}}$ Collaborative Innovation Center on Forecast and Evaluation of Meteorological Disasters, Nanjing University of Information
} Science and Technology, Nanjing, China

(Manuscript received 16 January 2021, in final form 29 September 2021)

\begin{abstract}
In this study, interannual and interdecadal variations in the extreme high-temperature event (EHE) frequency over northern Asia (NA) and the associated possible mechanisms are explored. On an interannual time scale, the first two empirical orthogonal function modes of the NA EHE frequency exhibit a meridional dipole pattern (EOF1) and diagonal tripolar pattern (EOF2), respectively. The higher NA EHE frequency is related to anomalous local highs, reduced mid- to low clouds, and more solar radiation. The warmer ground further heats the overlying atmosphere through longwave radiation and sensible heat. The warm temperature advection in the lower troposphere and the drier soil conditions also favor higher EHE frequency. Further analysis reveals that the EOF1 mode is related to the Polar-Eurasian teleconnection pattern (POL), while the EOF2 mode is associated with North Atlantic Oscillation (NAO) and Pacific-Japan/East AsiaPacific pattern (PJ/EAP). The fitted EHE frequency based on the atmospheric factors (POL, NAO, and PJ/EAP) can explain the interannual variation in the regionally averaged EHE frequency by $33.8 \%$. Furthermore, three anomalous sea surface temperature (SST) patterns over the North Atlantic-Mediterranean Sea region and around the Maritime Continent are associated with the two EHE modes by intensifying the pronounced atmospheric teleconnections. Analysis on the simulation of five models in the Atmospheric Model Intercomparison Project experiment further confirms the impact of the pronounced SST patterns on the POL, NAO and PJ/EAP. In addition, NA EHE frequency experienced a significant interdecadal increase around the mid-1990s, which could be associated with the phase shift of the Atlantic multidecadal oscillation and long-term global warming trend.
\end{abstract}

KEYWORDS: Asia; Atmospheric circulation; Extreme events; Sea surface temperature; Summer/warm season

\section{Introduction}

As one of the most devastating events occurring in summer, extreme high-temperature events (EHEs) exert significant impacts on human health and the natural environment (Easterling et al. 2000; Ciais et al. 2005; Shaposhnikov et al. 2014; Lu and Chen 2016). In recent decades, EHEs have been occurring more frequently across the world under the background of global warming (Meehl and Tebaldi 2004; Alexander et al. 2006; IPCC 2013), and several intense EHEs have been recorded. For instance, in 2003, an unprecedented heat wave caused the death of more than 22000 people and crop losses of approximately 12.3 billion dollars across Europe (Schär and Jendritzky 2004). In 2010, a rare mega-heatwave struck western Russia and caused over 55000 deaths and a total economic loss of 15 billion dollars (Barriopedro et al. 2011). In 2013, a recordbreaking heat wave occurred in southeastern China, bringing direct economic losses of approximately 59 billion RMB (about 9 billion U.S. dollars) and affecting the lives of more than half a billion people (Sun 2014; Sun et al. 2014). Meanwhile, the EHE frequency is projected to significantly and globally increase under future global warming (Tebaldi et al. 2006; Orlowsky and Seneviratne 2012; Chen and Sun 2018). Therefore, it is crucial to clarify the variation in EHEs and the

Corresponding author: Jianqi Sun, sunjq@mail.iap.ac.cn related mechanisms, which benefits the improvement of climate prediction and disaster prevention.

As the largest and most populous continent worldwide, Asia suffers from summer EHEs every year. From the perspective of the climatic state, EHEs (defined based on the absolute threshold method) occur most frequently in the mid- and lowlatitude regions of Asia (Hu and Huang 2020). In terms of the temporal variation, most areas of Asia have experienced a significant increasing trend in EHE frequency (Zhai and Pan 2003; Meehl and Tebaldi 2004; Alexander et al. 2006; Brown et al. 2008; Huang et al. 2010; Morak et al. 2013). In addition to the consistent increasing trend, some studies have detected interdecadal variations in the EHE frequency in different regions of Asia. It has been shown that EHEs occurred more frequently in the 1960s and 1980s in southern China, in the 1960s and 1990s in central China, and in the 1990s in northern China (Sun et al. 2011). There were significant interdecadal shifts in the EHE frequency over the middle and lower reaches of the Yangtze River basin around the early 1970s and the early 2000s ( $\mathrm{Li}$ and Sun 2018), southern China around the late 1980s (Fischer et al. 2012), northeastern Asia and western Asia around the mid-1990s (Dong et al. 2016; Shi et al. 2019), and central Asia around the late 1990s (Yu et al. 2020). Furthermore, the interannual variation in the EHE frequency has varied regionally. The EHE frequency shows opposite variations in northeastern China and southern China on an interannual time scale (Zhu et al. 2020a). It is revealed that virtually all April EHEs 
in Southeast Asia occurred during El Niño years (Thirumalai et al. 2017), while fewer (more) EHEs took place in central Asia and northeastern Asia during El Niño (La Niña) years (Luo and Lau 2020).

Previous studies have pointed out the outstanding effects of local high pressure systems on the formation of EHEs (Yang and Li 2005; Sun et al. 2011; Wang et al. 2014; Perkins 2015; Horton et al. 2016; Lu and Chen 2016; Wang et al. 2016; Luo and Lau 2017; Li and Sun 2018; Gao et al. 2018; Ding et al. 2018). Anomalous highs induce EHEs in the following two ways: 1) by intensifying adiabatic subsidence, which warms the air directly, and 2) by decreasing the cloud cover and allowing more solar radiation to reach and warm the surface, which further heats the surface air by diabatic heating. In addition, lowlevel temperature advection (Sun et al. 2011; Ziv et al. 2004; Harpaz et al. 2014) and variation in the upper-level westerly jet also contribute to EHE formation (Sun 2014; Wang et al. 2016; Li and Sun 2018; Hong et al. 2020). In terms of land-atmosphere interactions, lower soil moisture conditions also impact the EHE frequency because soil moisture largely determines the partitioning of net radiation fluxes in latent and sensible heat fluxes (Black et al. 2004; Fischer et al. 2007; Zampieri et al. 2009; Alexander 2011; Miralles et al. 2014; Horton et al. 2016).

In addition to the influence of local factors, remote factors also play important roles in Asian EHE frequency variations. Among the remote factors, the impacts of prominent atmospheric teleconnections have been emphasized (e.g., Walker and Bliss 1932; Wallace and Gutzler 1981; Barnston and Livezey 1987; Nakamura and Fukamachi 2004; Tachibana et al. 2004). For example, the variation in the EHE frequency in southeastern China is influenced by the circumglobal teleconnection (CGT; Ding and Wang 2005) on both interannual and interdecadal time scales (Wang et al. 2013; Li and Sun 2018). The Pacific-Japan/East Asia-Pacific pattern (PJ/EAP; Nitta 1987; Huang and Sun 1992) has been shown to influence the interannual variation in the EHE frequency over South Korea (Lee and Lee 2016). The connection between the North Atlantic Oscillation (NAO) and the EHE frequency in northern China has been explored (Sun 2012). In addition, boundary layer forcings can also modulate the Asian EHE variability. For instance, anomalous sea surface temperatures (SSTs) over the midlatitude North Atlantic Ocean have been shown to excite a zonal Rossby wave train and lead to mega heatwaves over southeastern China in 2013 (Sun 2014). The ability of the Pacific decadal oscillation to drive the interdecadal variation in EHE frequency over southern China by inducing a strengthened Walker circulation has been explored (Zhu et al. 2020b). El Niño-Southern Oscillation (ENSO) also impacts the EHE frequency in North America, eastern Europe/central Asia, and northeastern Asia by influencing the CGT mode and shifting the location of the jet stream (Luo and Lau 2020). In addition to the impact of anomalous SST patterns, reductions in Arctic sea ice content can also modulate Northern Hemisphere atmospheric circulation and lead to an increase in the EHE frequency (Budikova et al. 2019; Zhang et al. 2020).

Previous studies have mainly focused on the mid- and lowlatitude regions of Asia, where EHEs occur most frequently. Because of the high latitudes and relatively low temperatures, fewer EHEs take place in northern Asia (NA), and less attention has been given to EHE variations in this region. However, NA is sensitive to global warming (Sanderson et al. 2011), and more EHEs in this region can cause severe damage to fragile ecological environments, such as the degradation of Siberian permafrost, the destruction of vegetation, and the occurrence of forest fires. Recently, a piece of news from the World Meteorological Organization (WMO) regarding EHEs aroused public concern: the temperature of Verkhoyansk (a Siberian town located north of the Arctic Circle) reached $38^{\circ} \mathrm{C}$ on 20 June 2020, breaking historical temperature records in the Arctic Circle (https://public.wmo.int/en/media/news/reported-newrecord-temperature-of-38\% C2\%B0c-north-of-arctic-circle). Currently, we have little knowledge on the EHE variation in NA. Under such a situation, at least two questions arise: what are the dominant variation features of EHEs in NA over the past half century, and what are the possible physical mechanisms responsible for these variations? Motivated by these questions, the dominant interannual and interdecadal variations in the EHE frequency in NA are examined, and then the related large-scale patterns of atmospheric circulation and SSTs are explored.

The paper is organized as follows. The data and methods are introduced in section 2. The dominant modes of interannual variation in the summer EHE frequency in NA and the related local formation mechanisms are investigated in section 3 . The impacts of atmospheric teleconnections and SST patterns on the dominant modes are presented in section 4 . The fitting results obtained based on atmospheric factors are shown in section 5. The interdecadal variation in the NA summer EHE frequency and the possible mechanisms are explored in section 6 . Finally, a summary of the results and a discussion are presented in section 7 .

\section{Data and method}

\section{a. Datasets}

To investigate the spatiotemporal variations in the summer EHE frequency in NA over the period of 1960-2018, daily maximum surface air temperature $\left(T_{\max }\right)$ data are derived from 204 meteorological stations in NA. In this paper, NA is defined as the region over $40^{\circ}-75^{\circ} \mathrm{N}, 60^{\circ}-140^{\circ} \mathrm{E}$, covering the Asian parts of Russia, Mongolia, northern China, eastern Kazakhstan, Kyrgyzstan, central Uzbekistan, and northern Tajikistan. The longitude of $60^{\circ} \mathrm{E}$ is used as the western boundary of NA because it is roughly the border between Asia and Europe. In addition, as reviewed in the introduction, previous studies have focused on the variations of EHE frequency over the mid- to low latitudes of Asia (south of $40^{\circ}$ N; e.g., Sun et al. 2011; Fischer et al. 2012; Li and Sun 2018; Deng et al. 2019; Zhu et al. 2020a). Therefore, here we will focus on the region north of $40^{\circ} \mathrm{N}$. Among the 204 total stations, data of the 151 stations (shown in Fig. 1 as red dots) located outside of China are obtained from the Global Historical Climatology Network-Daily (GHCN-D; Menne et al. 2012) version 3.27, which contains numerous daily records from more than 100000 stations in 180 countries and territories. The summer season refers to 


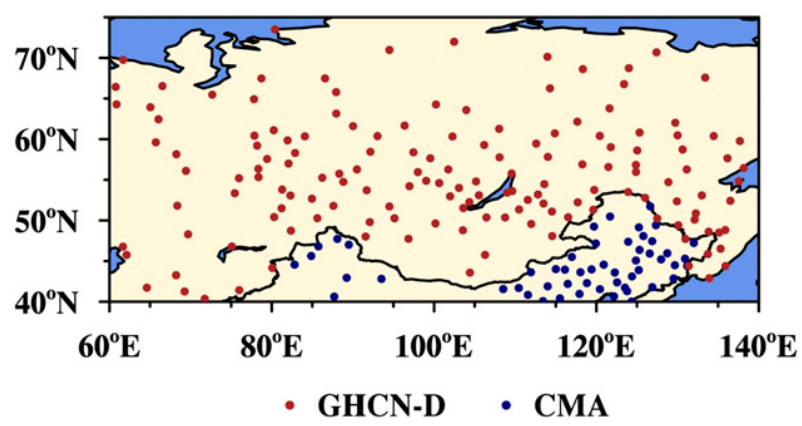

FIG. 1. Graphical distribution of 204 meteorological stations in northern Asia $\left(40^{\circ}-75^{\circ} \mathrm{N}, 60^{\circ}-140^{\circ} \mathrm{E}\right)$. The 151 red ( 53 blue) dots represent the weather stations, data of which are derived from GHCN-D (CMA).

June-August (JJA) in this paper, and stations with less than $5 \%$ missing data in JJA were used; thus, 151 stations were selected. The missing $T_{\max }$ data were replaced by the climatological average value of the given day over 1960-2018. The number of valid Chinese stations in GHCN-D was more than 50 before 2013, but the number decreased rapidly from 53 in 2013 to 15 in 2018. Therefore, data from 53 Chinese stations (covering the period of 1960-2013 in GHCN-D; shown in Fig. 1 as blue dots) obtained from the China Meteorological Administration (CMA; http://data.cma.cn) are applied here. Finally, the graphical distribution of all meteorological stations is shown in Fig. 1, and the merged dataset is named GHCND-CMA in this paper.

The Berkeley Earth Surface Temperatures (BEST) data incorporate more than 5000 meteorological stations and allow the incorporation of short and fragmented time series (Rohde et al. 2013). The BEST dataset has a horizontal resolution of $1^{\circ} \times 1^{\circ}$ and covers the period from 1850 to the present. The $T_{\max }$ data from BEST are also applied in this paper to compare with the results obtained based on the GHCND-CMA data.

To diagnose the atmospheric circulations related to the variations in NA EHE frequency, a monthly atmospheric dataset covering the period of 1960-2018, obtained from the Japanese 55-year Reanalysis (JRA-55), is employed (Kobayashi et al. 2015). The dataset has a horizontal resolution of $1.25^{\circ} \times$ $1.25^{\circ}$ and is available in 37 specific levels from 1000 to $1 \mathrm{hPa}$. The meteorological variables involved in this study include the geopotential height, horizontal wind, vertical velocity, cloud cover, net surface shortwave radiation, net surface longwave radiation, sensible heat, air temperature, and surface soil moisture. In this study, positive (negative) radiation fluxes suggest the downward (upward) direction. The soil moisture data in JRA-55 are available at three depths, which vary with vegetation. Because the soil moisture at the upper layer influences the EHE occurrence more directly than the soil moisture at the deeper layers, the soil moisture at the top layer is used in this paper to represent the surface soil moisture.

To further study the impacts of oceanic forcings on NA EHEs, monthly SST data derived from the Hadley Centre Global Sea Ice and Sea Surface Temperature dataset (HadISST; Rayner et al. 2003) are used. The SST dataset has a horizontal resolution of $1^{\circ} \times 1^{\circ}$ and covers the period from 1870 to the present.

Because EHEs mainly occur in summer over the Northern Hemisphere, in this study the summer season is the focus. Therefore, the aforementioned meteorological elements have been averaged over JJA to investigate the NA EHE-related atmospheric circulations and SST patterns.

\section{b. Definition and methods}

There are generally two types of EHE definitions: the absolute threshold definition (e.g., $35^{\circ} \mathrm{C}$ ) and the relative threshold definition (e.g., 90\%, 95\% quantile). Considering the large domain and relatively high-latitude region of NA, the absolute threshold may not be suitable for NA EHE-related research. Therefore, following previous studies (e.g., Meehl and Tebaldi 2004; Alexander et al. 2006; Fischer and Schär 2010), the relative threshold definition of the $95 \%$ quantile is used in this study. For a target day within JJA, its $T_{\max }$ threshold is defined as the 95th percentile of $T_{\max }$ for a total of 885 days $(15 \times 59$; 15 days cover 7 days on each side of the target day) in the 59 years from 1960 to 2018. An EHE is identified when the $T_{\max }$ on the target day exceeds its $T_{\max }$ threshold. By using the 15-day moving time window, the influence of synoptic systems is weakened, and the temporal evolution of the EHE threshold can be more consecutive (Fischer and Schär 2010; Deng et al. 2019).

The NAO index used in this paper is downloaded from the Climate Prediction Center (https://www.cpc.ncep.noaa.gov/ data/teledoc/teleintro.shtml) and is defined as the standardized principal component (PC) of the NAO pattern. The NAO pattern is achieved as the leading mode, by applying the rotated PC analysis to monthly mean $500-\mathrm{hPa}$ geopotential heights over Northern Hemisphere $\left(20^{\circ}-90^{\circ} \mathrm{N}\right)$. The Atlantic multidecadal oscillation (AMO) index is downloaded from National Oceanic and Atmospheric Administration Physical Sciences Laboratory (NOAA PSL; https://psl.noaa.gov/data/ timeseries/AMO/) and is defined as the area weighted average SST over North Atlantic $\left(0^{\circ}-70^{\circ} \mathrm{N}\right.$; Enfield et al. 2001), from which the long-term trend over the period from 1948 to the present has been removed.

To capture the dominant feature of the summer NA EHE frequency, empirical orthogonal function (EOF; Lorenz 1956) analysis is applied to the NA EHE frequency over the period of 1960-2018. The leading EOF modes are tested by the rule of North et al. (1982). Applying EOF analysis can reveal the dominant variations in EHEs frequency, but the variation on different time scales could be mixed in the EOF result. To separate interannual and interdecadal variations, we apply the Lanczos filter (Duchon 1979) before further analysis. The Lanczos filter has been widely used in EHE-related research (e.g., Chen et al. 2018; Zhu et al. 2020a; Luo and Lau 2020; Li et al. 2020), and in this paper, the 9-yr high-pass (low-pass) filter is used to obtain the interannual (interdecadal) variation in the time series. According to the proposal in Duchon (1979), the 9-yr high-pass (low-pass) filter applies an 11-point moving time window for a better filtering effect. Due to substantial reduction in the degrees of freedom of the 9-yr low-pass filtered time series, the effective degrees of freedom $N_{e}$ are estimated by the following formula: 
(a) EOF1

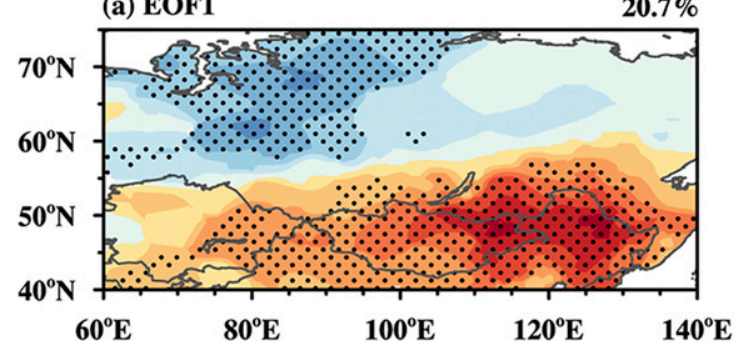

(b) PC1

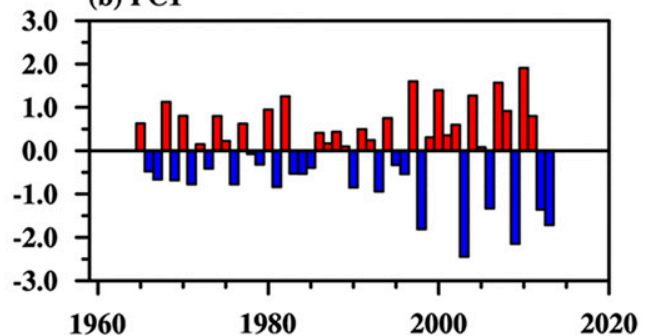

(d) PC2

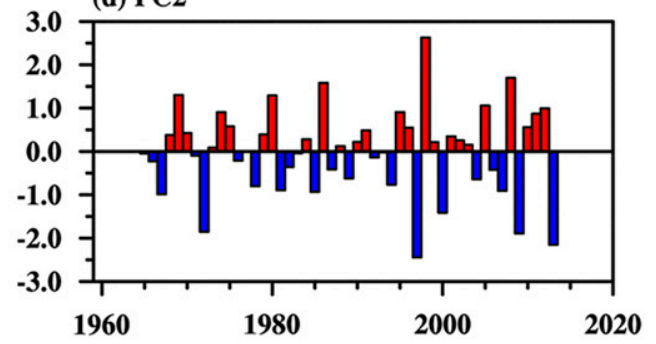

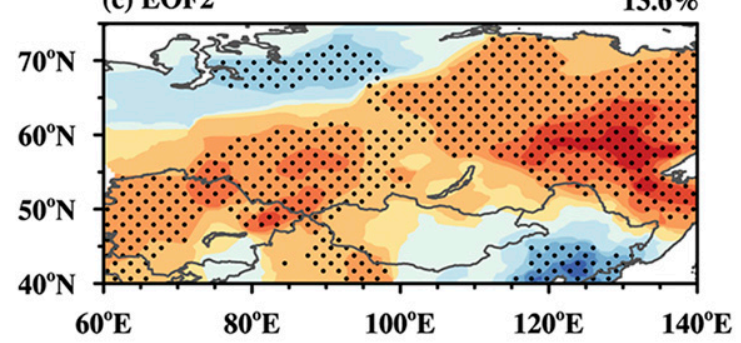

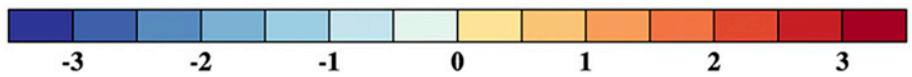

FIG. 2. The (a) first and (c) second leading mode of the 9-yr high-pass filtered NA EHE frequency, defined as the regression map of the EHE frequency against the corresponding PCs over the period of 1965-2013. The standardized time series of (b) PC1 and (d) PC2 over the period of 1965-2013. The explained variance to the total variance of each mode is shown in the top-right corner of (a) and (c). Dotted areas in (a) and (c) are significant at the $95 \%$ confidence level based on the Student's $t$ test.

$$
N_{e}=\frac{N}{1+2 \sum_{i=1}^{10} a_{i} b_{i}},
$$

where $N$ represents the length of the 9-yr low-pass filtered time series, and $a_{i}$ and $b_{i}$ represent the autocorrelation at lag $i$ for the time series of $a$ and $b$, respectively (Quenouille 1952).

To show the direction of wave energy propagation, the wave activity flux is employed according to the method proposed by Takaya and Nakamura (2001). The horizontal component of the wave activity flux is expressed as follows:

$\mathbf{W}=\frac{p}{2 a^{2}|\mathbf{U}|}\left\{\begin{array}{l}\frac{\bar{u}}{\cos \varphi}\left[\left(\frac{\partial \psi^{\prime}}{\partial \lambda}\right)^{2}-\psi^{\prime} \frac{\partial^{2} \psi^{\prime}}{\partial \lambda^{2}}\right]+\bar{v}\left[\frac{\partial \psi^{\prime}}{\partial \lambda} \frac{\partial \psi^{\prime}}{\partial \varphi}-\psi^{\prime} \frac{\partial^{2} \psi^{\prime}}{\partial \lambda \partial \varphi}\right] \\ \bar{u}\left[\frac{\partial \psi^{\prime}}{\partial \lambda} \frac{\partial \psi^{\prime}}{\partial \varphi}-\psi^{\prime} \frac{\partial^{2} \psi^{\prime}}{\partial \lambda \partial \varphi}\right]+\bar{v} \cos \varphi\left[\left(\frac{\partial \psi^{\prime}}{\partial \varphi}\right)^{2}-\psi^{\prime} \frac{\partial^{2} \psi^{\prime}}{\partial \varphi^{2}}\right]\end{array}\right\}$.

In the above equation, the overbars and primes indicate the average climatic states and deviations from the climate states, respectively; $p$ is the normalized pressure (pressure per 1000 $\mathrm{hPa}) ; \mathbf{U}=(\bar{u}, \bar{v})$ represents the summer average horizontal wind velocity; $\psi^{\prime}$ is the perturbation streamfunction; $\lambda$ and $\varphi$ denote the longitude and latitude, respectively; and $a$ is Earth's radius.

To further verify the role of the North Atlantic SST patterns in the formation of the pronounced Rossby wave trains, the Rossby wave source (RWS) is calculated according to Sardeshmukh and Hoskins (1988):

$$
\mathrm{RWS}=-\nabla\left(V_{\chi} \cdot \xi_{a}\right)
$$

where $V_{\chi}$ represents the divergent wind and $\xi_{a}$ is the absolute vorticity.

\section{Dominant modes of interannual variation in NA EHE frequency and related local atmospheric circulations}

\section{a. Dominant modes of interannual variation in the NA} EHE frequency

To focus on the interannual variation and remove the interdecadal variation, the 9-yr high-pass Lanczos filter was applied to the NA EHE frequency time series. In this study, the spatial and temporal features of the NA EHE frequency are investigated from the aspect of the leading EOF modes. To reflect the significant regions, the EOF modes are defined as the regression maps of the 9-yr high-pass filtered EHE frequency against the corresponding PCs in this paper. Figure 2 shows the two leading EOF modes and the related PCs. These two EOF modes account for $20.7 \%$ and $13.6 \%$ of the total interannual variation in the EHE frequency, and they can be significantly separated from each other and from other modes based on the criterion outlined in North et al. (1982).

As shown in Fig. 2a, the first EOF mode (EOF1; EOF2 hereafter refers to the second modes) reflects a meridional dipole pattern over NA, approximately divided by the line of latitude at $55^{\circ} \mathrm{N}$. The negative (positive) anomalies lie in the northern (southern) part of NA with a significant anomaly center located to the west of the Yenisei River (northeast China). According to the wavelet analysis and power spectrum 
(a) $\mathbf{Z 5 0 0}$

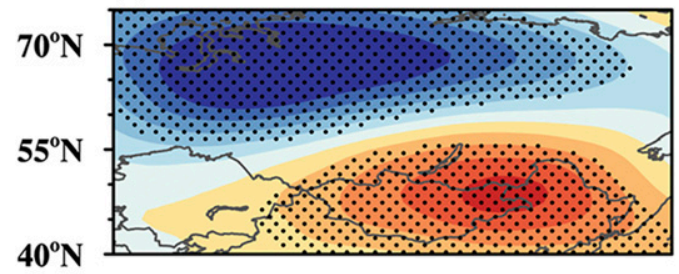

(c) MLCC

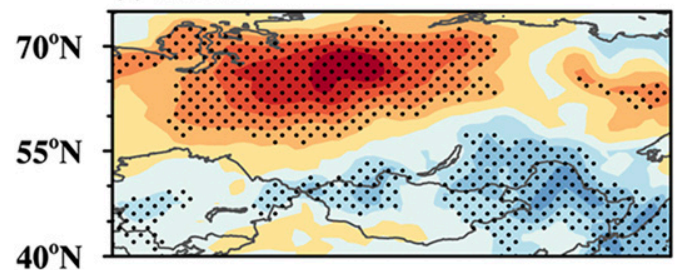

(e) SM

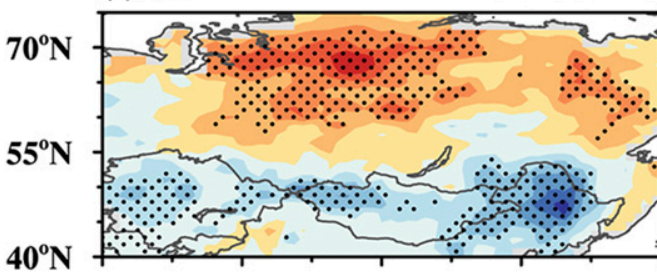

(b) $\mathrm{Z500}$

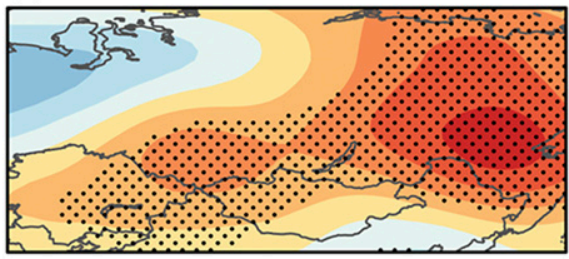

(d) MLCC

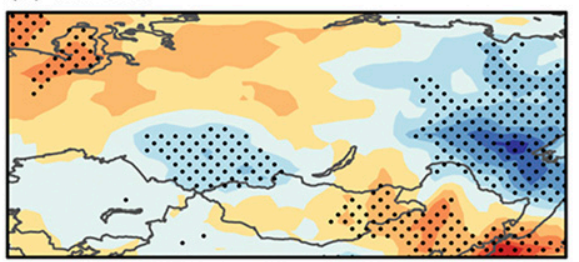

(f) $\mathrm{SM}$

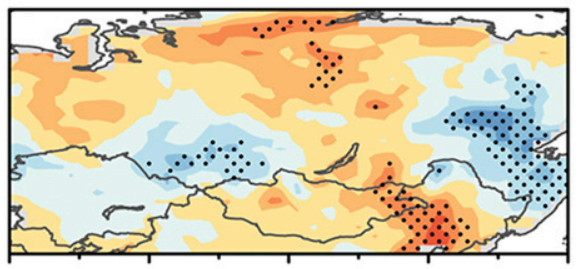

$120^{\circ} \mathrm{E} \quad 140^{\circ} \mathrm{E}$

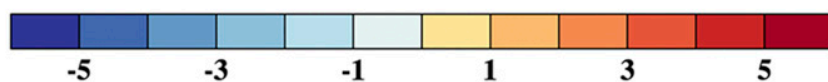

FIG. 3. Regression maps of 9-yr high-pass filtered JJA-mean (a),(b) 500-hPa geopotential heights (units: 3 gpm), (c),(d) middle and low cloud cover (units: \%), and (e),(f) soil moisture (units: \%) against (left) PC1 and (right) PC2 over the period of 1965-2013. Dotted areas are significant at the 95\% confidence level based on the Student's $t$ test.

analysis results (figure not shown), the PC of EOF1 (PC1; PC2 hereafter refers to the PC of EOF2) is dominated by 2-4-yr quasi-periodic oscillations. Meanwhile, the oscillation amplitude of PC1 shows an interdecadal amplification around the mid1990s, with standard deviation increasing from 0.66 over 1969-93 to 1.35 over 1995-2009 (the decadal difference in standard deviations is significant at $99 \%$ confidence level based on the Student's $t$ test), which coincides with the interdecadal phase shift in the NA EHE frequency (shown in section 6).

The EOF2 mode shows a diagonal tripolar pattern, with negative signals in the northwestern and southeastern parts of NA and positive signals between these negative regions (Fig. 2c). In addition, the signals over the eastern part of NA are stronger than those over other regions, showing a meridional dipole pattern over eastern NA. The wavelet analysis and power spectrum analysis on PC2 (figure not shown) indicate that the PC2 is also dominated by 2-4-yr quasi-periodic oscillations. Similar to PC1, the variability of PC2 has an amplified amplitude around the mid-1990s as well.

\section{b. Local atmospheric circulations associated with the dominant modes of the interannual variation in the $N A$ EHE frequency}

Previous studies have revealed the outstanding role of high pressure systems in the middle and upper troposphere in the formation of EHEs (e.g., Black et al. 2004; Meehl and Tebaldi 2004; Sun et al. 2011; Li and Sun 2018; Zhu et al. 2020a; Hong et al. 2020). Hence, the summer mean 500-hPa geopotential height is first investigated here. Figures $3 \mathrm{a}$ and $3 \mathrm{~b}$ suggest that the positive (negative) geopotential height anomalies match well with the locations of higher (lower) EHE frequency in the two EOF modes. Variations in the local atmospheric circulation can influence EHE formation by modulating the land surface radiation budget. Specifically, the low-level divergent (convergent) flow accompanied by the anomalous anticyclone (cyclone) results in a decrease (increase) in middle and low cloud cover (Figs. 3c,d). The decreased (increased) cloud cover favors (hinders) more shortwave radiation reaching and heating the ground surface (Figs. 4a,b). Finally, the warm (cold) ground surface increases (decreases) the near-surface air temperature by enhanced (weakened) longwave radiation (Figs. 4c,d) and sensible heat (Figs. 4e,f), consequently contributing to the occurrence of EHE.

Besides heat flux, temperature advection in the lower troposphere could also be a factor for the formation of EHE. Therefore, the influence of temperature advection on the two EOF modes is further analyzed. The anomalous descending (ascending) motion-figure not shown-corresponding to the local anticyclone (cyclone) induces the warm (cold) vertical temperature advection (Figs. 5a,b); meanwhile, the anomalous 
(a) NSSRF

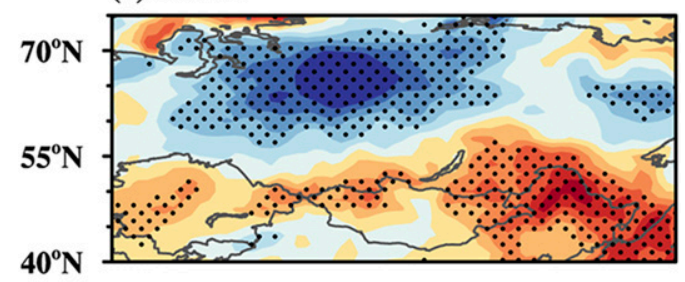

(c) NSLRF

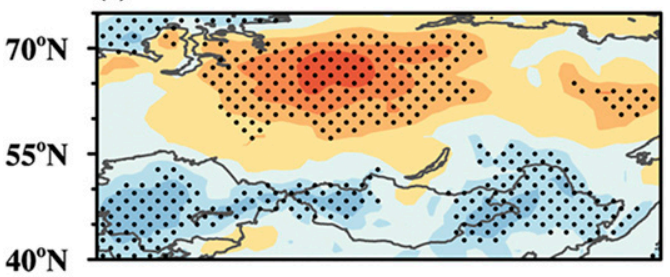

(e) SHF

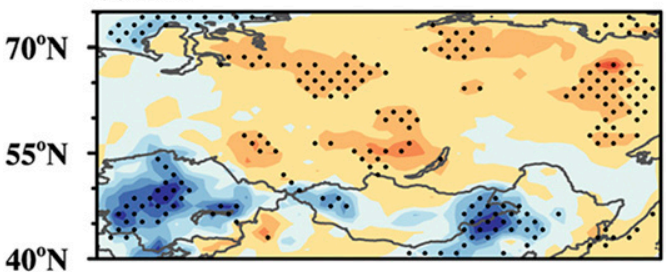

(g) NSLRF+SHF

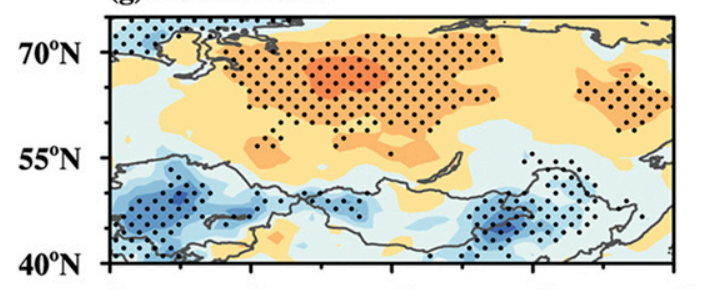

(b) NSSRF

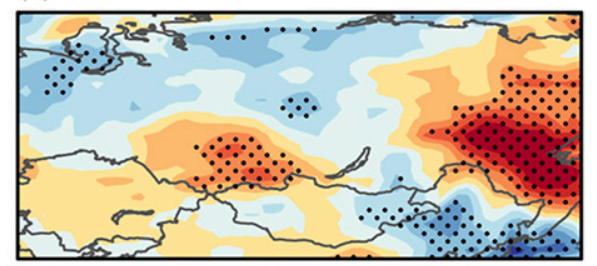

(d) NSLRF

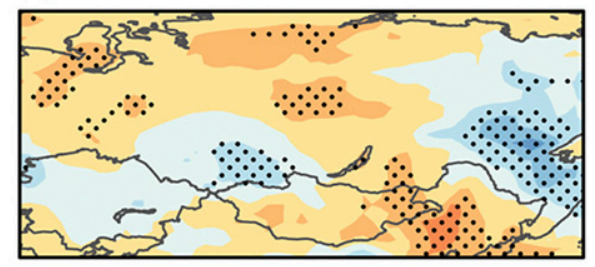

(f) SHF

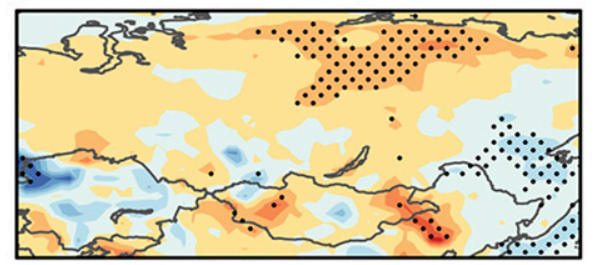

(h) NSLRF+SHF

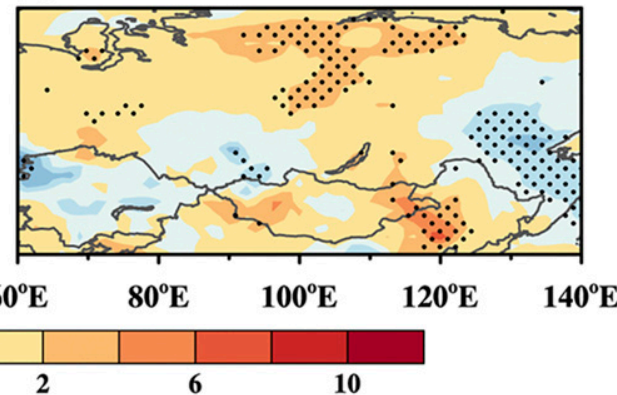

FIG. 4. Regression maps of 9-yr high-pass filtered JJA-mean (a),(b) net surface shortwave radiation flux (units: $\mathrm{W} \mathrm{m}^{-2}$ ), (c),(d) net surface longwave radiation flux (units: $\mathrm{W} \mathrm{m}^{-2}$ ), (e),(f) sensible heat flux (units: $\mathrm{W} \mathrm{m}^{-2}$ ), and (g),(h) the sum of net surface longwave radiation flux and sensible heat flux (units: $2 \mathrm{~W} \mathrm{~m}^{-2}$ ) against (left) PC1 and (right) PC2 over the period of 1965-2013. The positive and negative values in the figure represent the downward and upward flux anomalies, respectively. Dotted areas are significant at the 95\% confidence level based on the Student's $t$ test.

cyclone-related (anticyclone-related) horizontal winds in the lower troposphere can lead to anomalous horizontal temperature advection (Figs. 5c,d). The combination of vertical and horizontal temperature advection consequently contributes to the local EHE formation. For the EOF1 mode, the cold temperature advection over northwestern NA favors lower EHE frequency over the region, and warm temperature advection over midlatitude NA favors higher EHE frequency there (Fig. 5e). For the EOF2 mode, the anomalous temperature advections generally show a diagonal tripolar pattern, with cold temperature advections over the northwestern and southeastern parts of NA and warm temperature advections between them (Fig. 5f). Such a distribution of anomalous temperature advection is similar to that of EOF2 mode (Fig. 2c), consequently contributing to the formation of EHE EOF2 mode.
To further compare the relative contribution of diabatic heating and temperature advection to the formation of the two EHE modes, the pattern correlations are calculated. In doing so, the anomalies of heating flux (defined as the sum of net longwave radiation flux and sensible heat flux; Figs. 4g,h) and temperature advection (Figs. 5e,f) are first interpolated to 204 NA stations and then their pattern correlation coefficients with EOF1 and EOF2 pattern are calculated. The correlation coefficients of anomalous diabatic heating and temperature advection with the EOF1 (EOF2) pattern are 0.69 and 0.45 (0.43 and 0.65$)$. The results indicate that on the whole, the diabatic heating (temperature advection) contributes more to the formation of EOF1 (EOF2) mode.

In addition, the thermal conditions of the land also play important roles in the partitioning of net radiation (e.g., Fischer et al. 2007; Zampieri et al. 2009; Alexander 2011; Miralles et al. 2014; 
(a) Tadv850_vertical

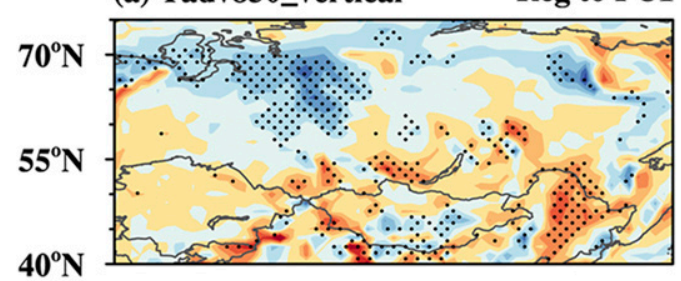

(c) Tadv850_horizontal

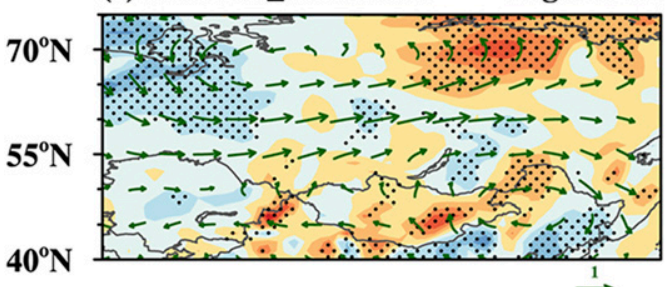

(e) Tadv850

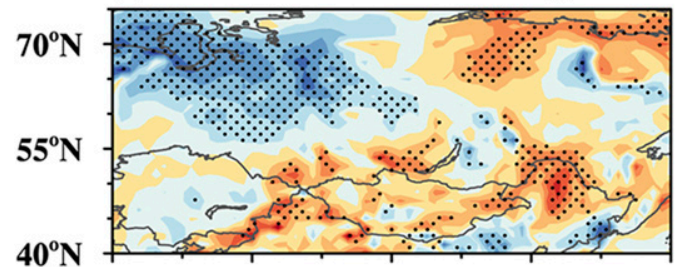

(b) Tadv850_vertical

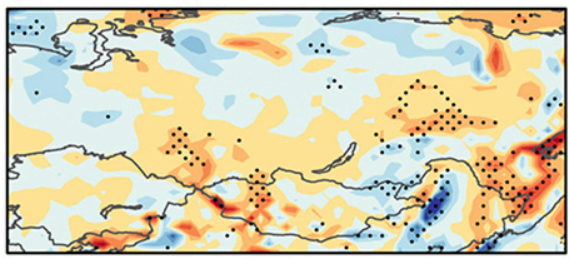

(d) Tadv850_horizontal

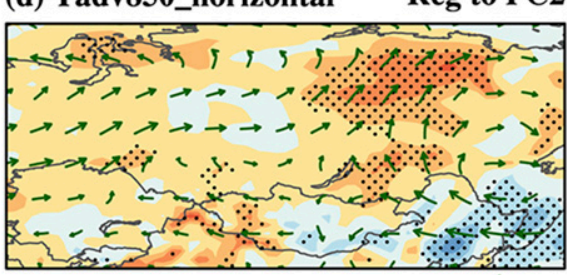

(f) Tadv850

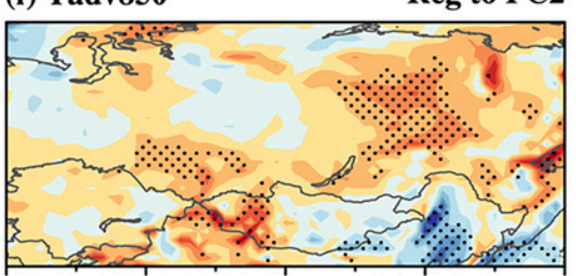

$60^{\circ} \mathrm{E}$

$80^{\circ} \mathrm{F}$

$100^{\circ} \mathrm{E}$

\begin{abstract}
$120^{\circ}$
\end{abstract}
$80^{\circ} \mathrm{E}$

$100^{\circ} \mathrm{E}$

$120^{\circ} \mathrm{E}$

$140^{\circ} \mathrm{E}$

$-5$

$-3$

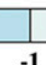

FIG. 5. Regression maps of 9-yr high-pass filtered JJA-mean (a),(b) vertical temperature advection (units: $10^{-7} \mathrm{~K} \mathrm{~s}^{-1}$ ), (c),(d) horizontal temperature advection (units: $10^{-7} \mathrm{~K} \mathrm{~s}^{-1}$ ), and (e),(f) total temperature advection (sum of horizontal and vertical temperature advection; units: $10^{-7} \mathrm{~K} \mathrm{~s}^{-1}$ ) at $850 \mathrm{hPa}$ against (left) PC1 and (right) PC2 over the period of 1965-2013. The positive (negative) values in the figure indicate the warm (cold) temperature advection. Dotted areas are significant at the $95 \%$ confidence level based on the Student's $t$ test.

Horton et al. 2016). As shown in Figs. 3e and 3f, the drier (wetter) soil moisture conditions correspond to the increase (decrease) of sensible heat flux (Figs. 4e,f) and the higher (lower) EHE frequency in the two EOF modes (Figs. 2a,c).

Therefore, through the aforementioned physical, radiative, and thermal processes, the pronounced local atmospheric circulations and the soil moisture conditions over NA are closely related to the variations in the leading modes of summer EHEs over the region.

\section{Impacts of atmospheric teleconnections and SST patterns on the dominant modes of interannual variation in NA EHE frequency}

a. The impacts of the polar-Eurasia teleconnection and SST anomalies in the North Atlantic and Mediterranean Sea on the EOF1 mode

From the perspective of atmospheric teleconnection, the PC1-related geopotential heights at $250 \mathrm{hPa}$ (the results at $500 \mathrm{hPa}$ are similar and not shown) and associated horizontal wave activity flux on interannual time scale are displayed in Fig. 6a. The figure suggests the EOF1 mode is dominated by a zonal barotropic wave train from the North Atlantic Ocean to
NA, with active centers located at the east coast of North America, south of Greenland, the eastern North Atlantic Ocean, western Europe, central Europe, the West Siberian Plain, and Mongolia. The PC1-related wave train reflects a quadrupole over the North Atlantic region. Over the Eurasian continent, the wave train first propagates northward to the polar region and then southward to southern NA, leading to the prominent dipole pattern over NA. The high consistency between Figs. $6 \mathrm{a}$ and $6 \mathrm{~b}$ reveals that the EOF1 mode may have a close relationship with the polar-Eurasia teleconnection (POL; Barnston and Livezey 1987) pattern. The influence of the POL pattern on atmospheric circulations over Eurasia has been revealed in previous studies (e.g., Yin et al. 2014; Gao et al. 2017; Li et al. 2020). Based on Fig. 6a, we define the POL index as follows:

$$
\begin{aligned}
\mathrm{POL}= & \frac{1}{2}\left[Z_{250}^{*}\left(45^{\circ}-55^{\circ} \mathrm{N}, 100^{\circ}-125^{\circ} \mathrm{E}\right)\right. \\
& \left.-Z_{250}^{*}\left(60^{\circ}-75^{\circ} \mathrm{N}, 65^{\circ}-110^{\circ} \mathrm{E}\right)\right],
\end{aligned}
$$

where $Z_{250}^{*}$ are the standardized and area-averaged 9-year highpass filtered summer 250-hPa geopotential height anomalies. PC1 and the POL index vary consistently over the period of 1965-2013 (Fig. 7b) and have a correlation coefficient of 0.86 (significant at 
(a) Z250
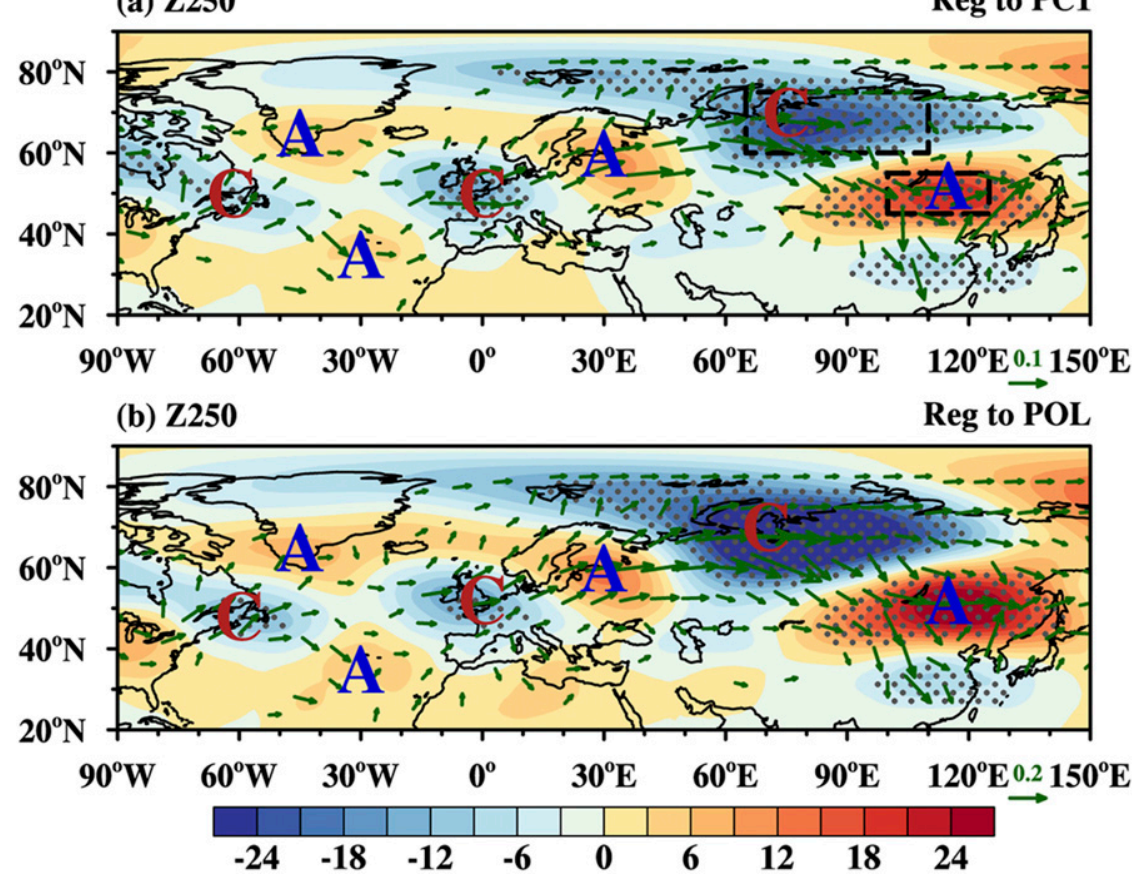

FIG. 6. Regression maps of 9-yr high-pass filtered JJA-mean geopotential heights (shading; units: gpm) against (a) PC1 and (b) the POL index at $250 \mathrm{hPa}$ and the related horizontal wave activity flux (vectors; units: $\mathrm{m}^{2} \mathrm{~s}^{-2}$ ) over the period of 1965-2013. Dotted areas are significant at the $95 \%$ confidence level based on the Student's $t$ test. Letters A and C indicate anomalous anticyclonic and cyclonic circulations, respectively. The dotted boxes in (a) indicate the key regions for the definition of the POL index.

the $99 \%$ confidence level based on the Student's $t$ test; the Student's $t$ test is applied in all the following significance tests).

The PC1-related wave train pattern shows eastward propagating wave activity flux over North Atlantic Ocean and Mediterranean Sea (Fig. 6a). Therefore, the PC1-related anomalous SST patterns are further explored in these regions. As shown in Fig. 7a, significant anomalous negative SST signals appear over the western midlatitude North Atlantic Ocean and the western part of the Mediterranean Sea. Based on Fig. 7a, the SSTI1 index is defined as follows:

$$
\begin{aligned}
\text { SSTI } 1= & \frac{1}{2}\left[\text { sst } *\left(40^{\circ}-50^{\circ} \mathrm{N}, 40^{\circ}-65^{\circ} \mathrm{W}\right)\right. \\
& \left.+\operatorname{sst}^{*}\left(35^{\circ}-50^{\circ} \mathrm{N}, 10^{\circ} \mathrm{W}-20^{\circ} \mathrm{E}\right)\right],
\end{aligned}
$$

where sst* represents the standardized and area-averaged 9-yr high-pass filtered summer SST anomalies over the region. The SSTI1 index is correlated to PC1 (POL), with a coefficient of $-0.54(-0.52)$, which is significant at the $99.9 \%(99.9 \%)$ confidence level. Figure $7 \mathrm{~b}$ further shows that the SSTI1 has consistent interannual variation with PC1 and POL over the period of 1965-2013. The SSTI1-related wave train pattern (Fig. 7c) shows a similarity with that of PC1 (Fig. 6a) and POL (Fig. 6b) over midlatitudes but difference over the northern polar region. The POL pattern is well known for characterizing the fluctuations in the strength of the polar vortex (e.g., Barnston and Livezey 1987; Claud et al. 2007; Balling and
Goodrich 2011; Gao et al. 2017) and the variation of polar vortex is the major forcing to the formation of POL. Therefore, the SSTI1-related SST anomaly pattern could favor the strengthening and maintenance of the North Atlantic-Eurasia part of the POL pattern, consequently exerting influence on the EOF1 mode of NA EHE frequency. The SSTI1-related RWS, velocity potential, and divergent wind at $250 \mathrm{hPa}$ are further shown in Fig. 7d. The anomalous RWS favors the formation of Rossby wave train and positive (negative) value of RWS corresponds to an increasing tendency of cyclonic (anticyclonic) vorticity. The advection of anomalous vorticity by the climatological flow tends to move the wave train pattern downstream (e.g., Kosaka and Nakamura 2006; Xu et al. 2019). Therefore, the anomalous action centers of the wave train pattern may locate in the downstream of the anomalous RWS. Figure 7d suggests a zonally quadrupole divergence pattern over the North Atlantic to Mediterranean Sea region, with anomalous convergences over the eastern coast of North America and eastern North Atlantic as well as divergences over western North Atlantic and Europe, respectively. Anomalous convergence (divergence) contributes to positive (negative) anomalous RWS, which further favors the formation of downstream anomalous cyclones over western North Atlantic and western Europe (anticyclones over eastern North Atlantic and central Europe), consequently exciting a wave train from the North Atlantic to East Asia (Fig. 7c). In addition, the southern route of SSTI1-related wave train pattern over Eurasia has some 
(a) SST

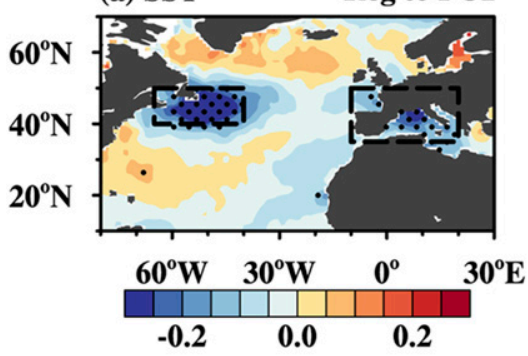

(c) $\mathbf{Z 2 5 0}$ (b) High Pass

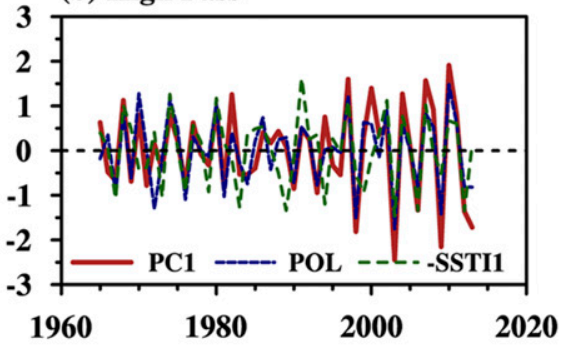

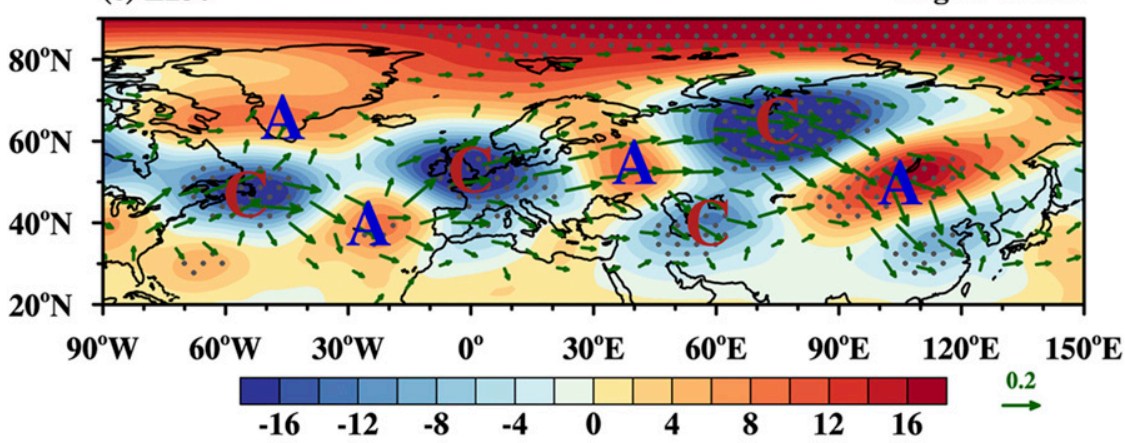

(d) WRS

Reg to -SSTI1

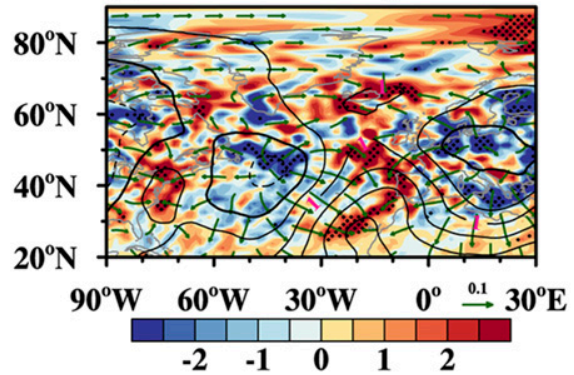

FIG. 7. (a) Regression map of 9-yr high-pass filtered JJA-mean SSTs (units: ${ }^{\circ} \mathrm{C}$ ) over the North Atlantic Ocean and Mediterranean Sea region against PC1, (c) 250-hPa geopotential heights (shading; units: gpm) against opposite signed SSTI1 and the related horizontal wave activity flux (vectors; units: $\mathrm{m}^{2} \mathrm{~s}^{-2}$ ), and (d) 250-hPa RWS (shading; units: $10^{-11} \mathrm{~s}^{-2}$ ), divergence wind (vectors; units: $\mathrm{m} \mathrm{s}^{-1}$ ), and velocity potential (contours; units: $5 \times 10^{4} \mathrm{~m}^{2} \mathrm{~s}^{-1}$ ) against opposite signed SSTI1 over the period of 1965-2013. (b) The standardized time series of PC1 (red curve), POL index (blue curve), and opposite signed SSTI1 (green curve) over the period of 19652013.SSTI1 is defined as the average SSTs in the two regions outlined by black dashed rectangles in (a). Letters A and C in (c) indicate anomalous anticyclonic and cyclonic circulations, respectively. Dotted areas are significant at the 95\% confidence level based on the Student's $t$ test.

similarities with that of the well-known Silk Road pattern (SRP; Enomoto 2004; Kosaka et al. 2009), indicating that the anomalous SST pattern could connect to the NA EHE EOF1 mode through changing the SRP.

The anomalous SST pattern shown in Fig. 7a is an inherent SST pattern over the North Atlantic, namely the third EOF mode of the interannual variation in SSTs (hereafter referred to as SST_EOF3, and SST_PC3 for the corresponding time series) over $20^{\circ}-65^{\circ} \mathrm{N}, 70^{\circ} \mathrm{W}-30^{\circ} \mathrm{E}$ (figure not shown). SST_EOF3 accounts for $13.31 \%$ of the total interannual variation in the North Atlantic SST. The spatial pattern of PC1-related anomalous SST pattern is similar to that of SST_EOF3 with a pattern correlation coefficient of 0.82 , and the correlation coefficient between SSTI1 and SST_PC3 is -0.78 (significant at the $99.9 \%$ confidence level). These results indicate that the inherent variability in SST pattern over North Atlantic is closely related to the EOF1 mode of NA EHE frequency.

b. The impacts of the NAO, EAP/PJ pattern, and SST anomalies in the North Atlantic Ocean and around the Maritime Continent on the EOF2 mode

Figure 8a shows the PC2-regressed 250-hPa geopotential height anomalies (the results at $500 \mathrm{hPa}$ are similar and not 
(a) $\mathbf{Z 2 5 0}$

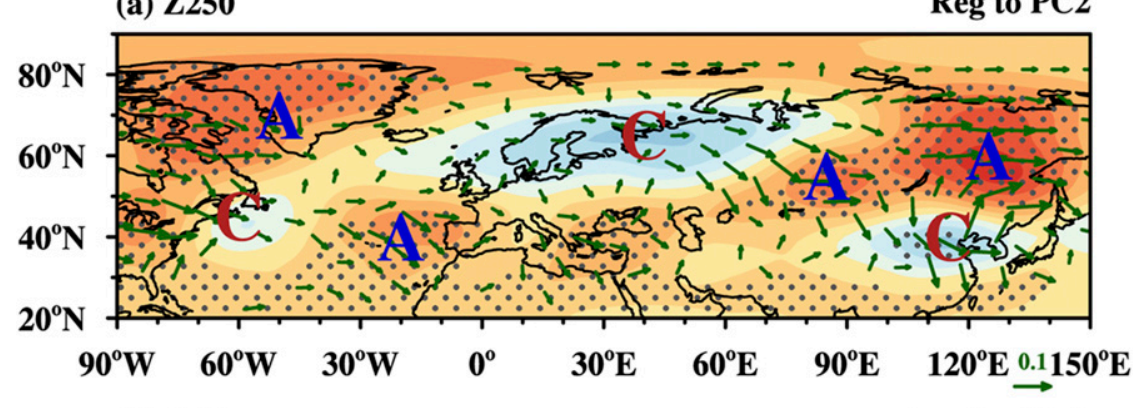

(b) $\mathbf{Z 2 5 0}$

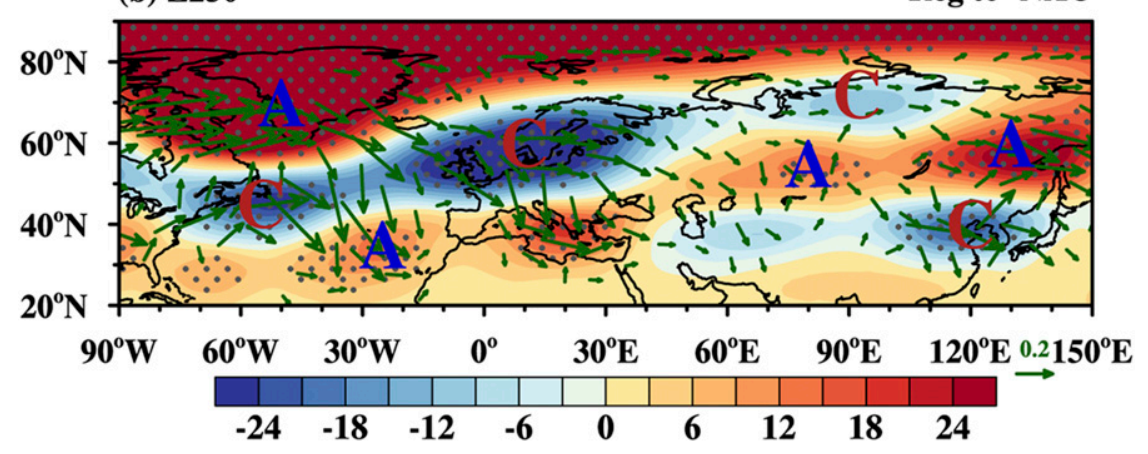

FIG. 8. As in Fig. 6, but (a) against PC2 and (b) against the opposite-signed NAO index. shown). There is a barotropic wave train propagating from the mid- to high latitudes of North Atlantic to NA with a southern route and a northern route. Along the southern route, anomalous alternate cyclones and anticyclones locate over the regions of western North Atlantic, eastern North Atlantic, northern Europe, southwestern-to-northeastern NA, and southeastern NA. In contrast, the northern route propagates from Greenland to NA through northern Europe. The PC2-related wave train resembles that of NAO (Fig. 8b). The NAO is a dominant atmospheric mode over the North Atlantic Ocean region and has great influences on atmospheric circulation around the Northern Hemisphere (e.g., Hurrell et al. 2003; Feldstein 2003; Grossmann and Klotzbach 2009). The NAO index is correlated to PC2, with a coefficient of -0.40 (significant at the $99 \%$ confidence level). The results shown in this paper suggest that the NAO may be associated with the diagonal tripolar pattern of EHE frequency over NA.

Previous studies have shown that the North Atlantic Tripolar (NAT) SST pattern is coupled well with the NAO (e.g., Czaja and Frankignoul 2002; Peng et al. 2003; Pan 2005; Chen et al. 2020). Therefore, PC2-related SSTs over the North Atlantic are examined, which exhibits a NAT-like pattern with significant positive anomalies at low and high latitudes and relatively weaker negative anomalies at middle latitudes (Fig. 9a). According to the SST anomalies shown in Fig. 9a, SSTI2 is defined as the averaged SST in the regions over $5^{\circ}-30^{\circ} \mathrm{N}, 80^{\circ}-40^{\circ} \mathrm{W}$ and over $52^{\circ}-65^{\circ} \mathrm{N}, 60^{\circ}-30^{\circ} \mathrm{W}$. The interannual variations in $\mathrm{PC} 2, \mathrm{NAO}$, and SSTI2 are shown in Fig. 9b. The SSTI2 is significantly correlated to PC2 and NAO, with coefficients of 0.48 and -0.51 , respectively (both are significant at $99 \%$ confidence level). To investigate the connection between the NAT SST pattern and the EOF2 mode, the SSTI2-regressed 250-hPa geopotential heights are shown in Fig. 9c. The figure suggests that the NAT SST pattern may enhance the negative phase of the $\mathrm{NAO}$, with an anomalous high in the Greenland region and an anomalous low in the western midlatitude North Atlantic Ocean. Moreover, the NAT SST pattern can stimulate a wave train (Fig. 9c) similar to the PC2-related wave train (Fig. 8a) and cause a diagonal tripolar pattern over NA. The SSTI2 is associated with anomalous convergences and positive RWSs over the eastern coast of North America and southern Greenland (divergences and negative RWSs over northeastern Canada and central North Atlantic; Fig. 9d). The anomalous positive (negative) RWSs induce the downstream anomalous cyclones over western North Atlantic and northern Europe (anticyclones over the Greenland and eastern North Atlantic), further stimulating a wave train (Fig. 9c). The results indicate that the NAT SST pattern could couple with the NAO and subsequently influence the EHEs occurring in the downstream region of NA.

In addition to the influences from the middle and high latitudes of the Northern Hemisphere, a significant meridional wave train from the tropical western Pacific Ocean associated with PC2 can also be found over East Asia in the lower troposphere, with two anomalous anticyclones located over northeastern NA and southern East Asia and an anomalous cyclone located over midlatitude East Asia (Fig. 10a). Such a wave train is the well-known PJ/EAP pattern (Nitta 1987; Huang and Sun 1992; Kosaka and Nakamura 2006; Lu and Lin 2009; Kosaka and Nakamura 2010; shown in Fig. 10b). 
(a) SST

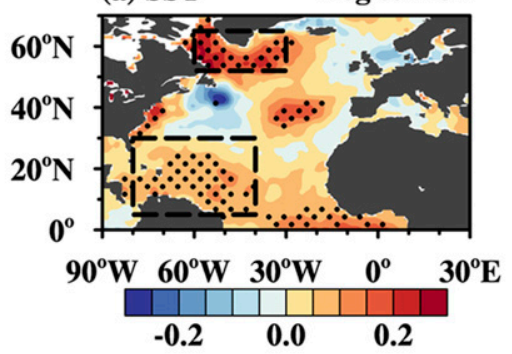

(c) $\mathbf{Z 2 5 0}$ (b) High Pass

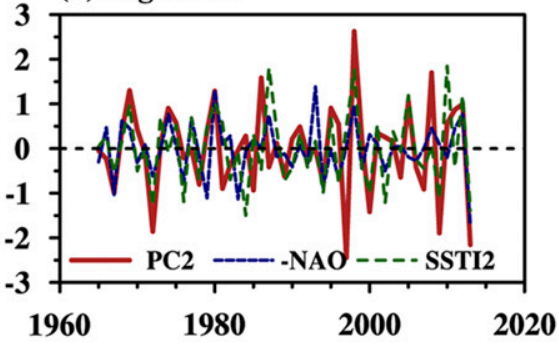

Reg to SSTI2

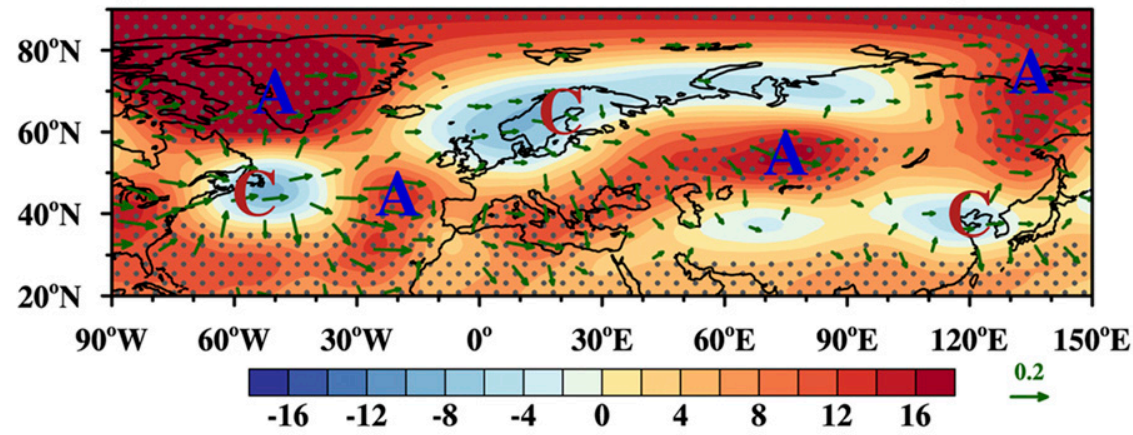

(d) WRS

Reg to SSTI2

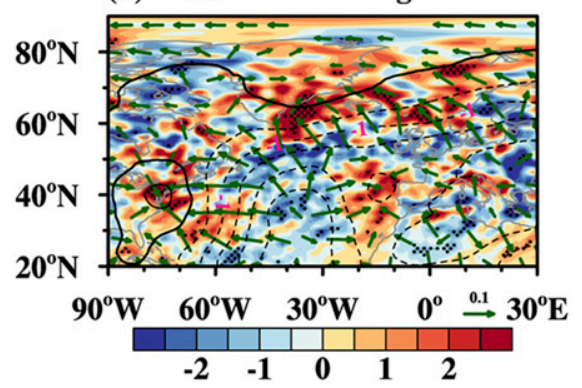

FIG. 9. As in Fig. 7, but (a) against PC2, (b) for PC2 (red curve), opposite-signed NAO (blue curve), and SSTI2 (green curve), and (c),(d) against SSTI2. SSTI2 is defined as the average SSTs in the two regions outlined by black dashed rectangles in (a).

Following the definition of Huang and Yan (1999), the EAP index is defined as follows:

$$
\begin{aligned}
\mathrm{EAP}= & {\left[-Z_{500}^{\prime}\left(20^{\circ} \mathrm{N}, 125^{\circ} \mathrm{E}\right)+2 Z_{500}^{\prime}\left(40^{\circ} \mathrm{N}, 125^{\circ} \mathrm{E}\right)\right.} \\
& \left.-Z_{500}^{\prime}\left(60^{\circ} \mathrm{N}, 125^{\circ} \mathrm{E}\right)\right] / 4,
\end{aligned}
$$

where $Z_{500}^{\prime}=\operatorname{Nor}\left(Z_{500} \sin 45^{\circ} / \sin \varphi\right)$ and $Z_{500}$ are the 9-yr highpass filtered summer 500-hPa geopotential height anomalies, $\varphi$ is the latitude, and $\operatorname{Nor}(x)$ is the standardization of $x$. The correlation coefficient between EAP and PC2 is -0.47 (significant at the $99 \%$ confidence level). The results suggest that the interannual variation in EAP may be associated with the dipole pattern of EHE frequency over eastern NA.

Because the PC2-related wave train pattern originates from the low latitudes (Fig. 10a), the PC2-related anomalies in SSTs and 500-hPa vertical velocity in the tropical western Pacific are further examined (Figs. 11a,b). The figure suggests that the anomalous warm SST pattern and enhanced convective activity over the Maritime Continent are correlated to the EOF2 mode. Therefore, a Pacific SST index (PSSTI2) is defined as the averaged SST in the region over $15^{\circ} \mathrm{S}-5^{\circ} \mathrm{N}, 90^{\circ}-140^{\circ} \mathrm{E}$. As shown in Fig. 11e, PC2 and PSSTI2 exhibit consistent variations during the past half century. The correlation coefficient between PSSTI2 and PC2 (EAP) is $0.34(-0.36)$, which is significant at the $95 \%$ (95\%) confidence level, further indicating a close relationship between PC2 and PSSTI2. The PC2-related and PSSTI2-related meridional circulations over $110^{\circ}-120^{\circ} \mathrm{E}$ (Figs. 11c,d) reflect that the positive values of $\mathrm{PC} 2$ and warm SSTs over Maritime Continent are associated with anomalous ascending motions over the Maritime Continent, indicating a strengthened convective activity. Therefore, the local Hadley circulation is significantly strengthened, which can enhance the Ferrel circulation, leading to anomalous meridional circulation over East Asia.

\section{c. Model validation}

To further validate the aforementioned connections between the anomalous SST patterns and the teleconnection 
(a) $\mathbf{Z 8 5 0}$

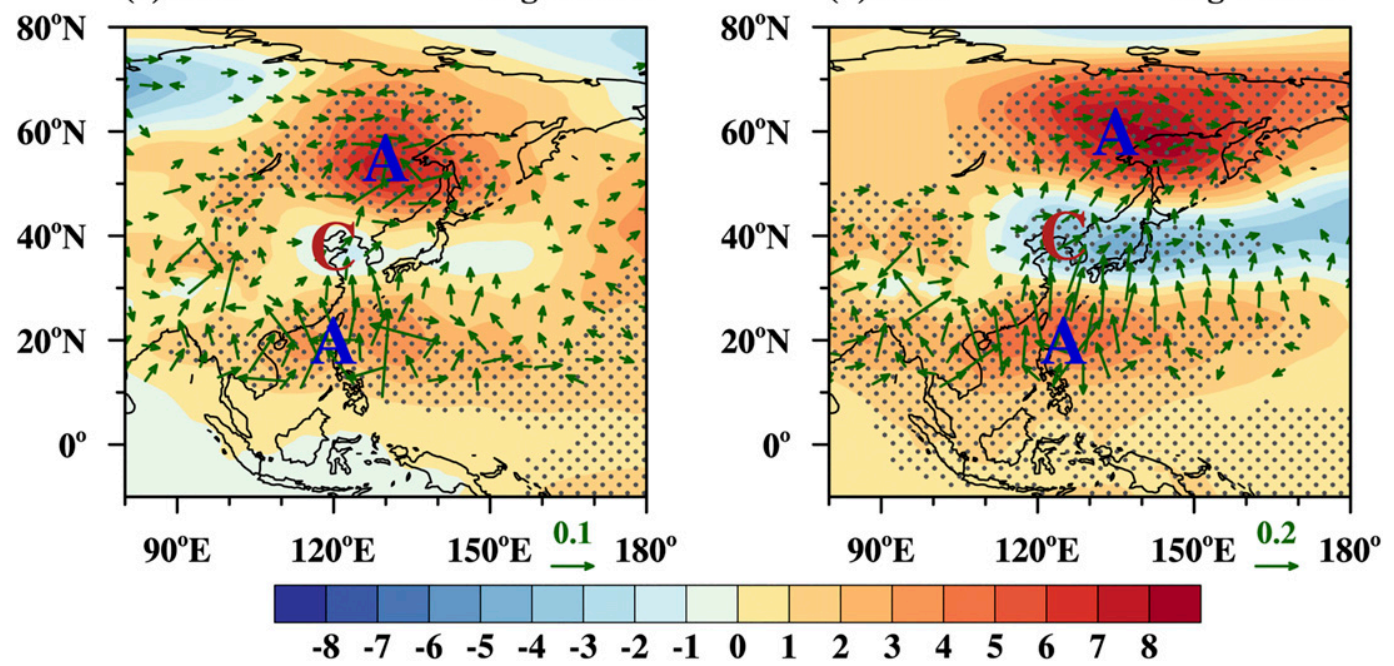

FIG. 10. Regression maps of 9-yr high-pass filtered JJA-mean 850-hPa geopotential heights (shading; units: gpm) against (a) PC2 and (b) opposite-signed EAP index and the related horizontal wave activity flux (vectors; units: $\mathrm{m}^{2} \mathrm{~s}^{-2}$ ) over the period of 1965-2013. Dotted areas are significant at the $95 \%$ confidence level based on the Student's $t$ test. Letters A and C indicate anomalous anticyclonic and cyclonic circulations, respectively.

patterns, the model outputs derived from Atmospheric Model Intercomparison Project experiments (AMIP) in phase 6 of the Coupled Model Intercomparison Project (CMIP6) are further analyzed. The AMIP simulations were forced by the observed SST and sea ice (Eyring et al. 2016), which are generally used to diagnose the response of atmospheric circulations to the anomalous SST or sea ice. In this study, the atmospheric circulations associated with the SST indices (SSTI1, SSTI2, and PSSTI2) in five AMIP models (ACCESS-CM2, BCCESM1, CESM2-FV2, CESM2-WACCM-FV2, and FGOALSf3-L) are analyzed and the ensemble mean results are shown in Fig. 12. Because of different covering period of the five model outputs, the common period of 1979-2014 is the focus here. Although the anomalous anticyclone over southeastern NA is weaker, the SSTI1-related teleconnection pattern in the AMIP simulations (Fig. 12a) is generally consistent with that in the observation (Fig. 7c). In addition, in the AMIP simulations, the SSTI2 is also associated with zonal wave train pattern from the mid- to high latitudes of the North Atlantic to NA (Fig. 12b), which is similar to observation (Fig. 9c). The AMIP models can generally simulate the PSSTI2-related EAP pattern over East Asia (Fig. 12d). However, compared to the observation result in Fig. 10b, the simulated location and intensity of the cyclone (anticyclone) in midlatitudes (high latitudes) have visible differences, which indicates that there could be more model uncertainties in the simulation of atmospheric circulations over mid- to high latitudes than low latitudes. In addition, such differences could also be attributable to other physical mechanisms that are not related to the SST anomalies. In conclusion, although there are some visible differences between the simulations and observations, the AMIP models can generally reproduce the observed atmospheric teleconnection patterns associated with the SST anomalies over the North Atlantic, the Mediterranean Sea, and around the Maritime Continent, further confirming the impact of these SST anomalies on the pronounced atmospheric teleconnection patterns.

As introduced above, the AMIP simulation is forced by global SSTs. To more clearly investigate the impact of the pronounced regional SST anomalies over the North Atlantic, the Mediterranean Sea, and around the Maritime Continent, further sensitivity numerical simulations using an atmospheric general circulation model (AGCM) should be performed in the future.

\section{Fitting results of the interannual variation in NA EHE frequency based on atmospheric teleconnection factors}

To address the question of how much of the interannual variation in the NA EHE frequency can be explained by the pronounced atmospheric teleconnections in the last section, the fitting results of the interannual variation in the NA EHE frequency based on these atmospheric teleconnection indices are investigated in this section. To do so, the fitted EHE frequency at each station is obtained based on the following formula:

$$
\operatorname{EHE}_{\mathrm{fit}}(i, j, t)=\mathrm{PC} 1 *(t) \times \operatorname{EOF} 1(i, j)+\mathrm{PC} 2 *(t) \times \operatorname{EOF} 2(i, j),
$$

where EOF1 and EOF2 are the first two leading modes of NA EHE derived from the observations; $i, j$, and $t$ denote the longitude, latitude, and time of a station, respectively. The $\mathrm{PC}^{*}$ ( $\left.\mathrm{PC} 2 *\right)$ is the fitted PC time series for EOF1 (EOF2) using the POL index (NAO and EAP indices) based on the linear regression. The spatial distribution of correlation coefficients between the fitted EHE frequency and the observed EHE frequency are shown in Fig. 13a. The figure suggests that, except for the small region over northern NA, the fitted 
(a) SST

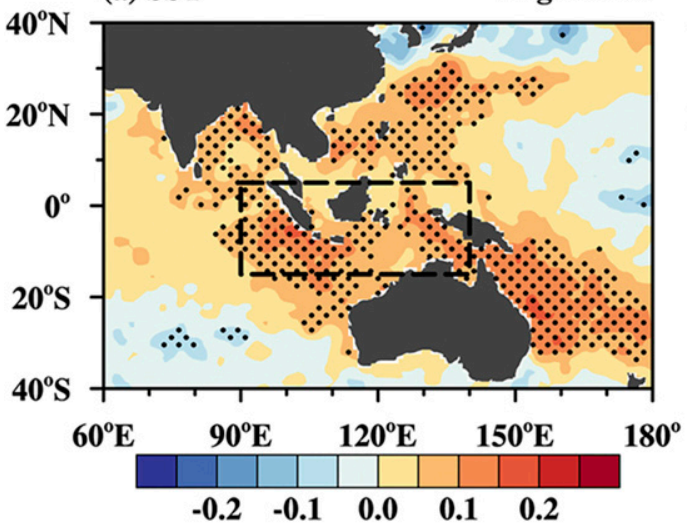

(c) Omega
Reg to PC2

Reg to PC2 (b) Omega_500

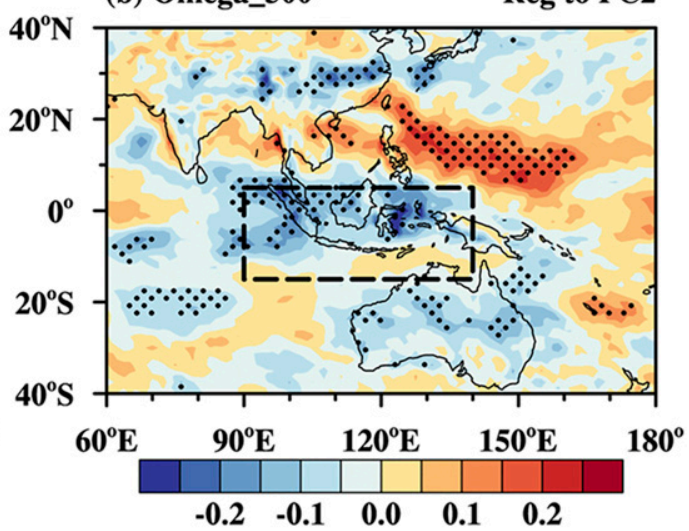

(d) Omega

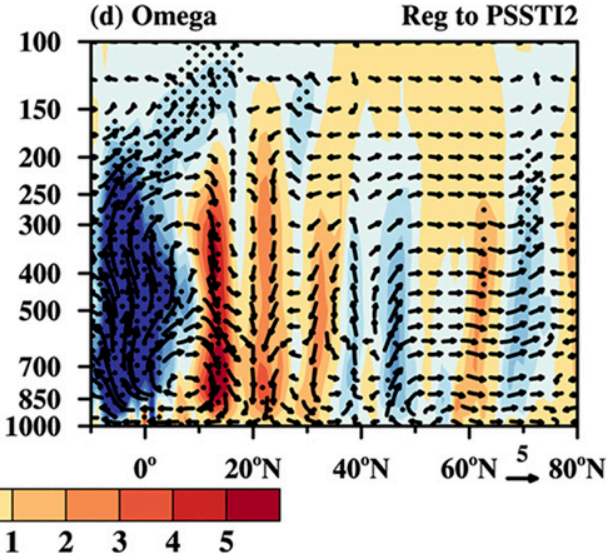

(e) High Pass

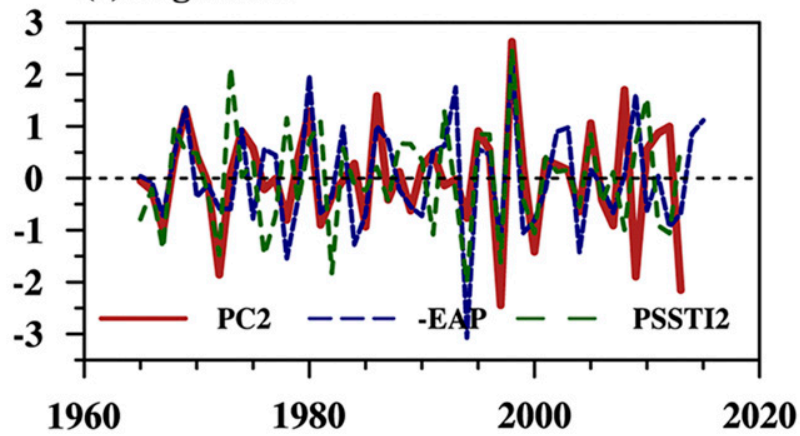

FIG. 11. Regression maps of 9-yr high-pass filtered JJA-mean (a) SSTs (units: ${ }^{\circ} \mathrm{C}$ ) and (b) 500-hPa vertical velocity (units: $10^{-3} \mathrm{~Pa} \mathrm{~s}^{-1}$ ) over the Maritime Continent region against PC2. (e) The standardized time series of PC2 (red curve), the opposite signed EAP index (blue curve), and PSSTI2 (green curve) over the period of 1965-2013. Also shown are latitude-pressure cross sections of the regression maps of the 9-yr high-pass filtered JJA-mean vertical motion (shading; units: $10^{-3} \mathrm{~Pa} \mathrm{~s}^{-1}$ ) and meridional circulations (vectors; meridional wind, units: $\mathrm{m} \mathrm{s}^{-1}$; vertical motion, units: $10^{-3} \mathrm{~Pa} \mathrm{~s}^{-1}$ ) against (c) PC2 and (d) PSSTI2 over the period of 19652013. The vertical motion and meridional circulations are averaged over $110^{\circ}-120^{\circ} \mathrm{E}$. PSSTI 2 is defined as the average SSTs in the region outlined by the black dashed rectangle in (a) and (b). Dotted areas are significant at the $95 \%$ confidence level based on the Student's $t$ test.

frequency shows good performance, with the highest correlation coefficient over southeastern and northwestern NA. The average fitted EHE frequency over NA is defined as the fitted EHE index. The fitted EHE index well covaries with the observed NA average EHE frequency on the interannual variation time scale
(Fig. 13b) and can explain $33.8 \%$ of the total interannual variation in the observed NA average EHE frequency. The results suggest that the atmospheric teleconnection factors explored in section 4 are good indicators of the interannual variation in the NA EHE frequency. 
(a) Z250 (1984-2009)

Reg to -SSTI1

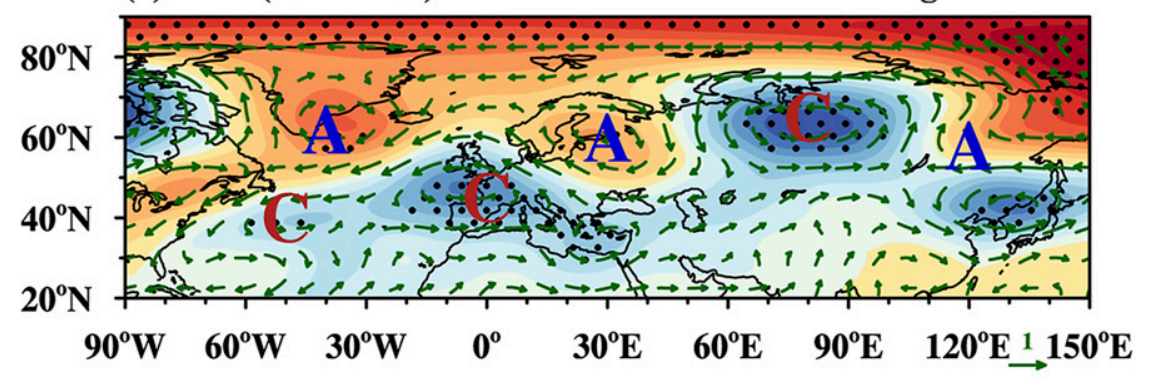

(b) Z250 (1984-2009)

Reg to SSTI2
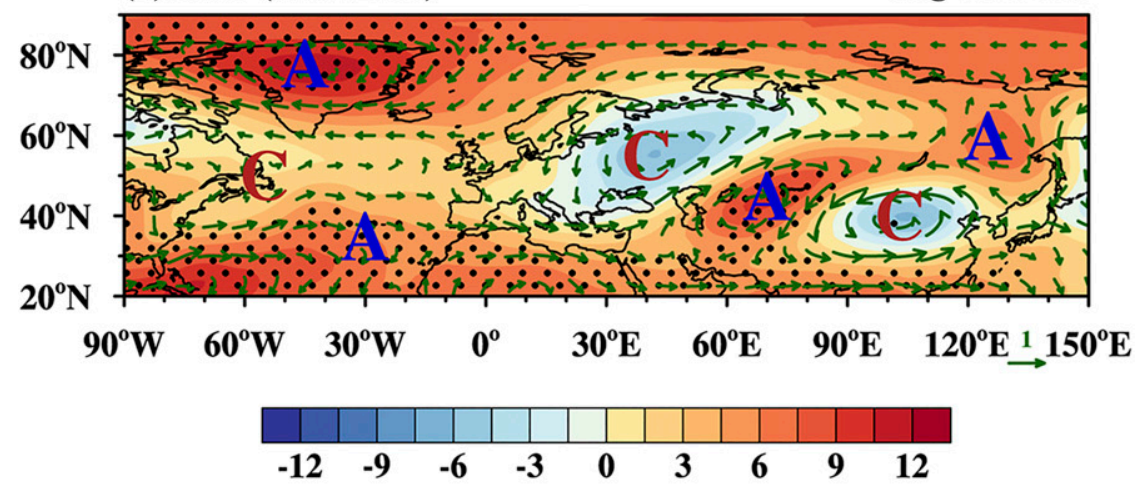

(c) Z850 (1984-2009) Reg to PSSTI2

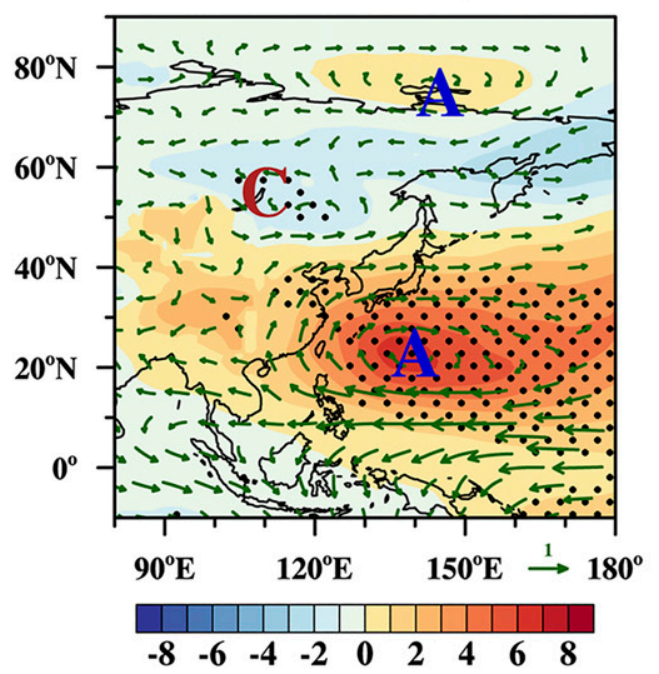

FIG. 12. Regression maps of 9-yr high-pass filtered JJA-mean geopotential heights (shading; units: gpm) and horizontal wind (vectors; units: $\mathrm{m} \mathrm{s}^{-1}$ ) against (a) opposite-signed SSTI1, (b) SSTI2 at $250 \mathrm{hPa}$, and (c) PSSTI2 at $850 \mathrm{hPa}$ over the period of 1984-2009 based on the ensemble mean results of five models from AMIP. Dotted areas are significant at the $95 \%$ confidence level based on the Student's $t$ test. Letters A and C indicate anomalous anticyclonic and cyclonic circulations, respectively.

\section{Interdecadal variation in NA EHE frequency and possible mechanism}

In addition to the pronounced interannual variation, the NA EHE frequency has significant interdecadal variation as well. We define the EHE index as the regional average EHE frequency over NA. As shown in Fig. 14a, the 9-yr low-pass filtered EHE index mainly reflects a strong interdecadal increase around the mid-1990s. Except for some areas over the northern part of NA, most areas of NA 
(a) Correlation coefficient

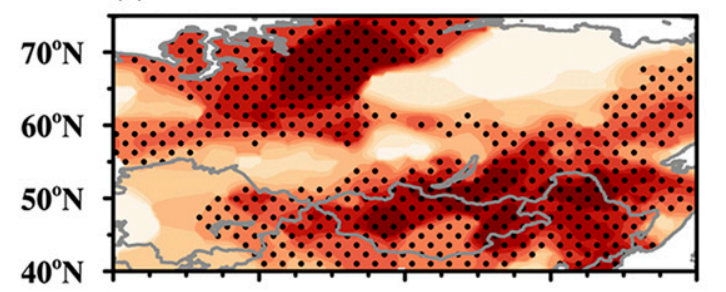

(b) Region_avg $\quad \mathbf{R}^{2}=\mathbf{3 3 . 8 \%}$

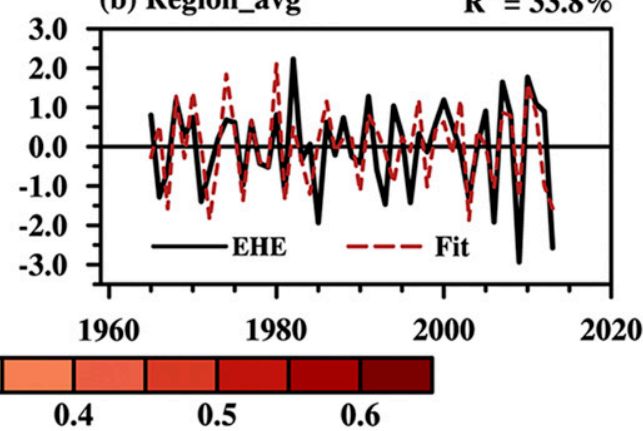

FIG. 13. (a) Correlation map of the 9-yr high-pass filtered NA EHE frequency and the fitted EHE frequency, and (b) the standardized time series of NA average the 9-yr high-pass filtered EHE frequency (black solid curve) and the fitted EHE index (red dotted curve) over the period of 1965-2013. Dotted areas in (a) are significant at the $95 \%$ confidence level based on the Student's $t$ test. The explained variance of the atmospheric fitting index to the total interannual variance in regional averaged EHE frequency is shown in the top-right corner of (b).

experienced an interdecadal increase around the mid1990s (Fig. 14b).

To investigate the favorable conditions for the interdecadal increase of NA EHE frequency, the EHE-related local atmospheric circulations and related heating processes are further diagnosed. As shown in Fig. 15, associated with increasing EHE frequency over NA, the geopotential heights are significantly enhanced over most regions of NA, favoring less midto low cloud cover there. The consequently anomalous heat fluxes and dry soil conditions favor the increasing EHE frequency over NA. Such conditions of interdecadal variation of NA EHE frequency are similar to those of interannual variation. Compared to the interannual variation, the temperature advection (Fig. 15i) contributes less to the interdecadal variation of NA EHE frequency.

The EHE index-related geopotential height anomalies in the middle and high troposphere are further examined and shown in Fig. 16. The most prominent feature of the figure is a strong anomalous high pressure system center locating over Mongolia and covering most areas of NA. The connection between the anomalous high pressure in Mongolia and interdecadal variation of NA EHE frequency has been discussed above. To further confirm this correlation, a high pressure index (HPI) is defined as the standardized average geopotential heights at $500 \mathrm{hPa}$ in the region over $40^{\circ}-55^{\circ} \mathrm{N}, 90^{\circ}-$ $120^{\circ} \mathrm{E}$. The correlation coefficient between the EHE index and HPI is 0.77 (significant at the $99 \%$ confidence level) over the period of 1960-2018, which shows consistent variation in the two indices on a year-to-year time scale. Furthermore, the correlation coefficient between the 9-yr low-pass filter indices reaches 0.95 , and the interdecadal increase in the HPI around the mid-1990s is consistent with that of the EHE index (Fig. 17b). The results indicate that the variation in geopotential height over Mongolia in the middle troposphere has a close relationship with that of the interdecadal variation of NA EHE frequency.

From the perspective of teleconnection pattern, the anomalous high over Mongolia is influenced by a zonal barotropic quasi-stationary Rossby wave train over Eurasia, which propagates from the North Atlantic Ocean downstream to NA (a) EHE_index

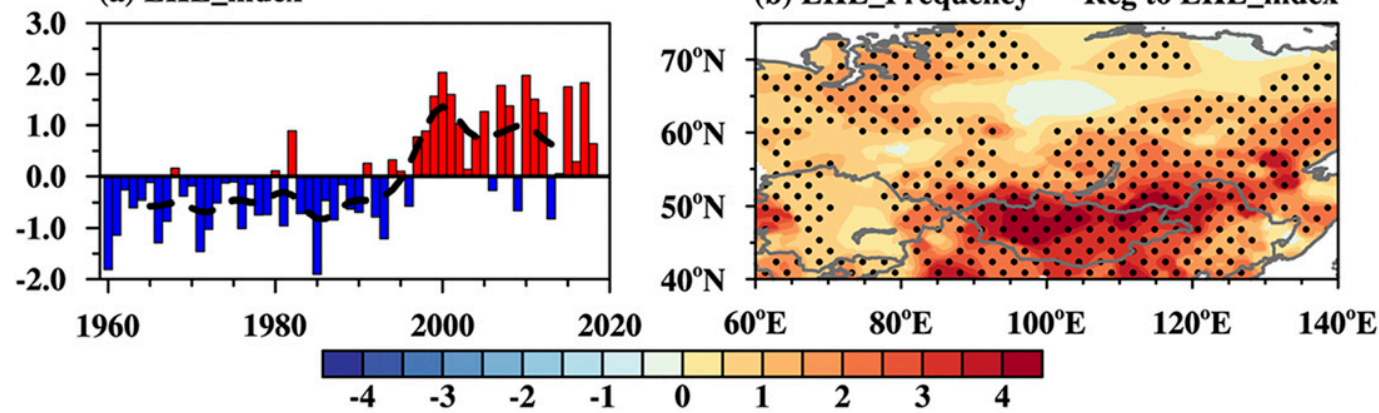

FIG. 14. (a) Standardized time series of the EHE index (black dashed line indicates the 9-yr low-pass filtered EHE index) over the period of 1960-2018. (b) Regression map of the 9-yr low-pass filtered EHE frequency against the 9-yr low-pass filtered standardized EHE index over the period of 1965-2013. Dotted areas in (b) are significant at the $95 \%$ confidence level based on the Student's $t$ test. 
(a) $\mathrm{Z500}$

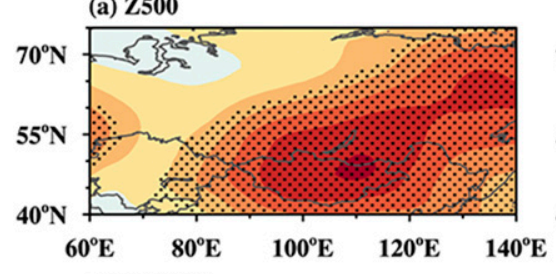

(d) NSLRF

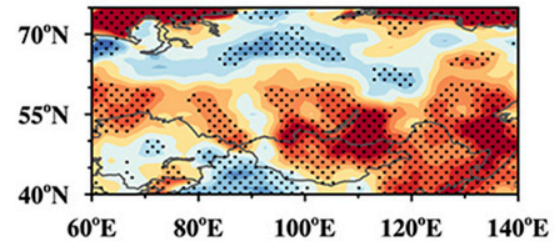

(g) Tadv850_ver

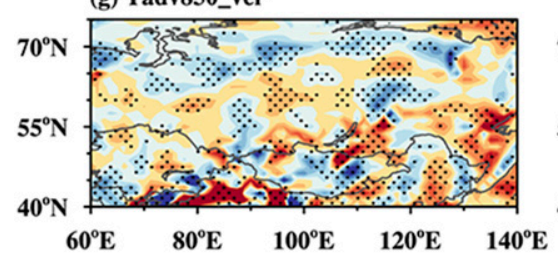

(b) MLCC

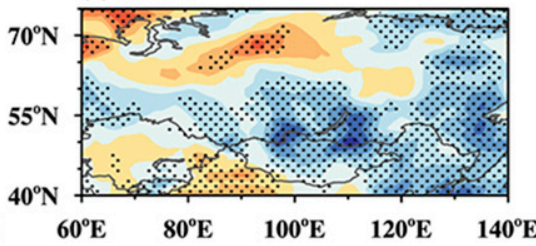

(e) SHF

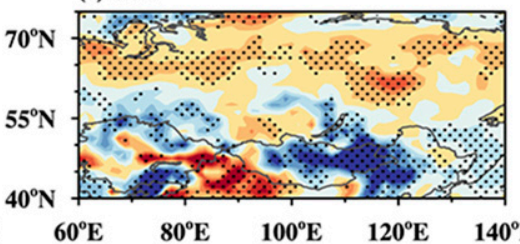

(h) Tadv850_hor

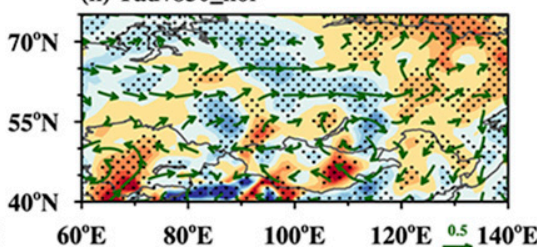

(j) $\mathrm{SM}$ (c) NSSRF

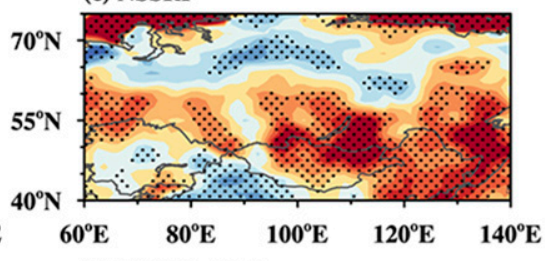

(f) NSLRF+SHF

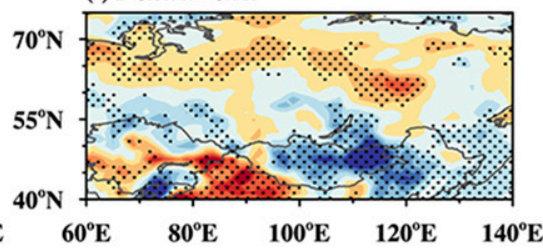

(i) Tadv850

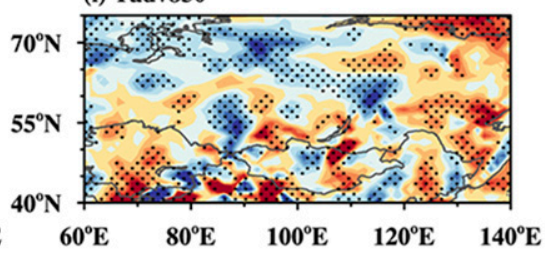

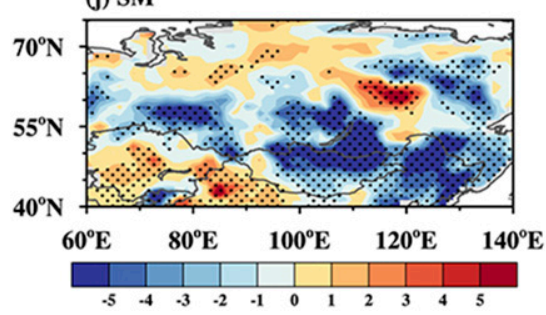

FIG. 15. Regression maps of 9-yr low-pass filtered JJA-mean (a) 500-hPa geopotential heights (units: 3 gpm), (b) middle and low cloud cover (units: \%), (c) net surface shortwave radiation flux (units: $\mathrm{W} \mathrm{m}^{-2}$ ), (d) net surface longwave radiation flux (units: $\mathrm{W} \mathrm{m}^{-2}$ ), (e) sensible heat flux (units: $\mathrm{W} \mathrm{m}^{-2}$ ), (f) the sum of net surface longwave radiation and sensible heat flux (units: $2 \mathrm{~W} \mathrm{~m}^{-2}$ ), (g) 850-hPa vertical temperature advection (units: $10^{-6} \mathrm{~K} \mathrm{~s}^{-1}$ ), (h) 850-hPa horizontal temperature advection (units: $10^{-6} \mathrm{~K} \mathrm{~s}^{-1}$ ) and horizontal wind (arrow; units: $\mathrm{m} \mathrm{s}^{-1}$ ), (i) 850-hPa total temperature advection (units: $10^{-6} \mathrm{~K} \mathrm{~s}^{-1}$ ), and (j) soil moisture (units: \%) against 9-yr low-pass filtered standardized EHE index over the period of 1965-2013. The positive and negative values in (c)-(f) represent the downward and upward flux anomalies, respectively. The positive and negative values in (g)-(i) indicate the warm and cold temperature advection, respectively. Dotted areas are significant at the $95 \%$ confidence level based on the Student's $t$ test.

(Fig. 16). This wave train has four prominent centers of action over the North Atlantic, central Europe, the West Siberian Plain/central Asia, and the Mongolian region. According to the wave activity flux shown in Fig. 16, the wave packet propagates from the North Atlantic Ocean to NA along two routes, the southern route and the northern route. Along the southern and northern routes, the wave packet propagates to Mongolia through the West Siberian Plain and central Asia, respectively.

The eastward propagation of the wave activity flux (Fig. 16) suggests that the EHE index-related wave train may originate from the North Atlantic Ocean and could be associated with variations in North Atlantic SSTs. Therefore, the EHE indexrelated anomalous SST pattern over North Atlantic Ocean is examined, which shows a typical AMO pattern (Schlesinger and Ramankutty 1994). The 9-yr low-pass filtered AMO index is significantly correlated to NA EHE index and HPI index, with coefficients of 0.88 and 0.80 , respectively. Furthermore, the concurrent interdecadal increases in EHE index, HPI index, and AMO index take place around the mid-1990s (Fig. 17b). Previous studies have shown that the AMO can influence the climate over Eurasia by modulating atmospheric circulation (e.g., Li and Bates 2007; Sun et al. 2015; Si and Ding 2016). The AMO-related geopotential heights at $500 \mathrm{hPa}$ (Fig. 17c) are consistent with that of NA EHE index (Fig. 16b). These results reveal that the phase shift of the AMO around the mid-1990s could be related to anomalous high pressure over Mongolia and the interdecadal increase of NA EHE frequency.

Recently, Hong et al. (2020) revealed that the EHE frequency over northeast China (the southeastern part of NA) experienced a similar interdecadal increase around the mid1990s, which is also associated with the phase shift of AMO. This study is an extension of Hong et al. (2020), showing that the interdecadal increase of EHE frequency around the 
(a) $\mathbf{Z 2 5 0}$

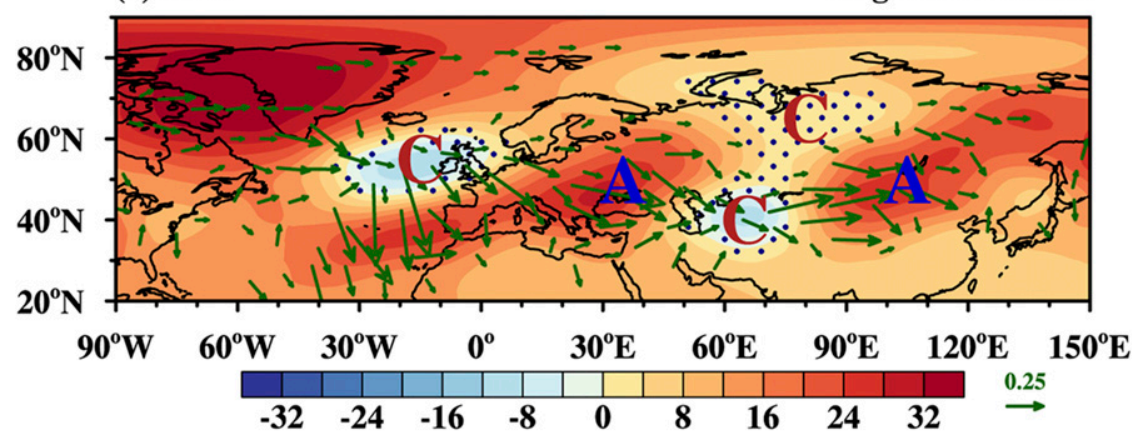

(b) $\mathbf{Z 5 0 0}$

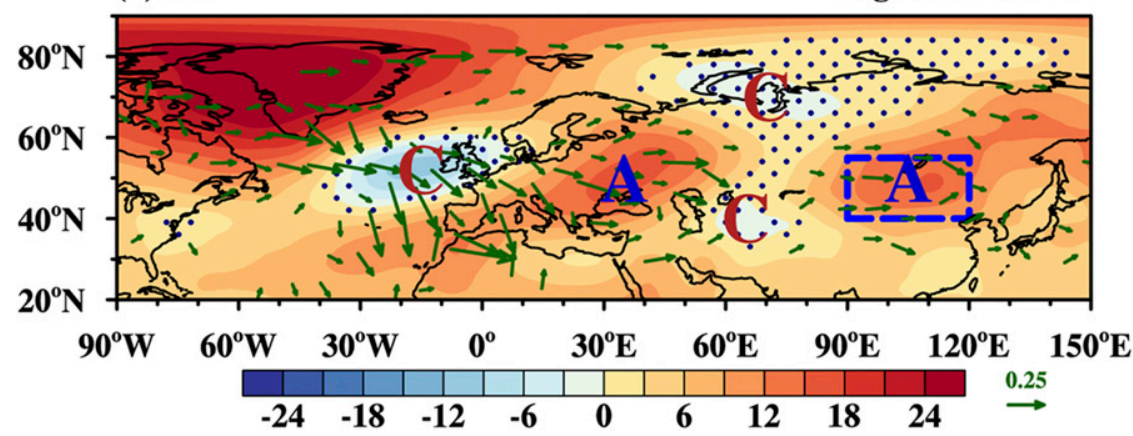

FIG. 16. Regression maps of 9-yr low-pass filtered JJA-mean geopotential heights (shading; units: gpm) against the 9-yr low-pass filtered standardized EHE index at (a) 250 and (b) $500 \mathrm{hPa}$ and the related horizontal wave activity flux (vectors; units: $\mathrm{m}^{2} \mathrm{~s}^{-2}$ ) over the period of 1965-2013. Dotted areas are insignificant at the $90 \%$ confidence level based on the Student's $t$ test. Letters A and C indicate anomalous anticyclonic and cyclonic circulations, respectively. The average geopotential heights at $500 \mathrm{hPa}$ over the blue dashed rectangle is defined as HPI.

mid-1990s is a wider phenomenon over NA, not only over northeast China.

In addition to the important contribution of the AMO, the observed increase in the EHE frequency over a large area of NA (Fig. 14b) may also be connected with global warming. As shown in Fig. 17b, besides the interdecadal increase around the mid-1990s, the EHE index also displays a long-term increasing trend over the past half century. Therefore, the detrended NA EHE frequency over the period of 1960-2018 is further investigated. After removing the long-term trend, the EHE index still exhibits an interdecadal variation and has an increase around the mid-1990s. In addition, the regression of 9-yr low-pass filtered and detrended 500-hPa geopotential heights against the 9-yr low-pass filtered and detrended EHE index also reflects an anomalous high pressure system over Mongolia (figure not shown), similar to Fig. 16, further indicating that the anomalous high pressure system plays an important role in interdecadal variation of NA EHE frequency. The result is further confirmed by the high correlation coefficient of 0.94 between 9-yr low-pass filtered and detrended HPI and EHE index and the concurrent interdecadal increase of the two indices around the mid-1990s (figure not shown).

After removing the long-term trend, the AMO-related wave train pattern still resembles the NA EHE-related wave train pattern (figure not shown). Moreover, the 9-yr low-pass filtered and detrended AMO index is still significantly correlated with the 9-yr low-pass filtered and detrended EHE index with a coefficient of 0.53 , and the 9-yr low-pass filtered and detrended AMO index also has a similar interdecadal increase around the mid-1990s (figure not shown). The results indicate that, after removing the long-term trend, the relationship between NA EHE frequency and AMO on interdecadal variation time scale still exists. However, compared to the detrended result, the 9-yr low-pass filtered and nondetrended AMO index shows more consistent variation with that of EHE index. Previous studies have indicated that the global warming trend caused mainly by the human activity plays an important role in the climate long-term variation (e.g., McCarthy et al. 2010; Gillett et al. 2008; IPCC 2013). Analysis of this paper suggests that the global warming trend and AMO could both contribute to the EHE variation over NA. Therefore, in the future, the climate change detection and attribution need to be further investigated to quantitatively measure the contributions of human activity and natural variability to the interdecadal variation in the NA EHE frequency.

\section{Conclusions and discussion}

In this study, the features of the spatial and temporal variations in the summer EHE frequency over NA are explored 
(a) SST Reg to EHE index

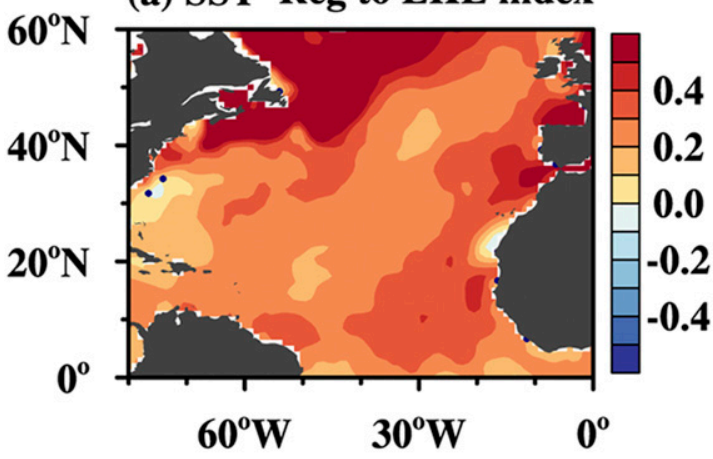

(c) $\mathbf{Z 5 0 0}$

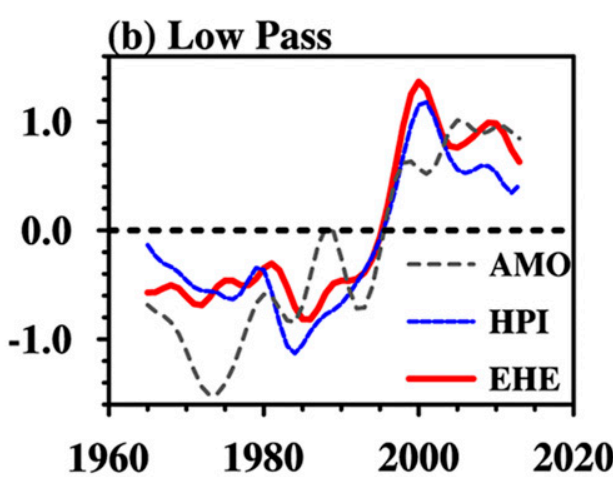

Reg to AMO index

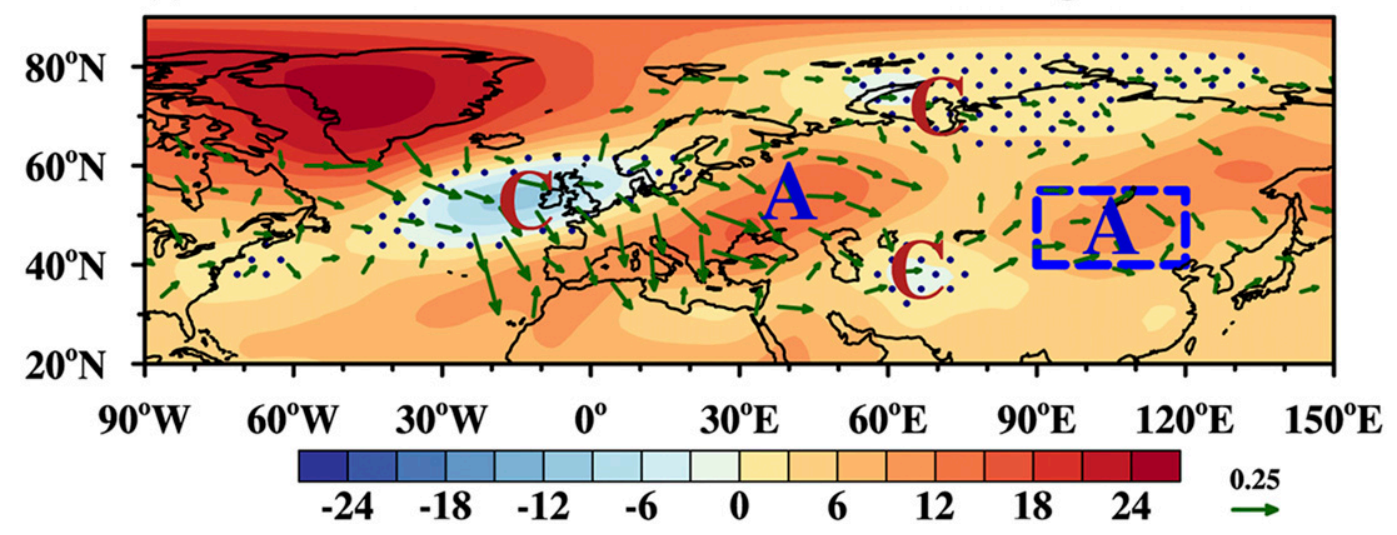

FIG. 17. Regression map of 9-yr low-pass filtered JJA-mean (a) SSTs (units: ${ }^{\circ} \mathrm{C}$ ) over the North Atlantic region against the 9-yr low-pass filtered EHE index, and (c) 500-hPa geopotential heights (shading; units: gpm) against the 9-yr low-pass filtered AMO index and the related horizontal wave activity flux (vectors; units: $\mathrm{m}^{2} \mathrm{~s}^{-2}$ ) over the period of 1965-2013. (b) The standardized time series of the 9-yr low-pass filtered EHE index, HPI index and AMO index over the period of 1965-2013. The average geopotential heights at $500 \mathrm{hPa}$ over the region outlined by the blue dashed line are defined as HPI. Letters A and C in (c) indicate anomalous anticyclonic and cyclonic circulations, respectively. Dotted areas are insignificant at the $90 \%$ confidence level based on the Student's $t$ test.

from the perspectives of interannual and interdecadal time scales, and the possible mechanisms for these variations are further investigated. The results deepen our understanding of NA EHE and favors the further climate prediction and disaster preparation.

The dominant interannual variation characteristics of NA EHE are researched using two leading EOF modes in this paper. The two modes display meridional dipole pattern (EOF1) and diagonal tripolar pattern (EOF2) over NA, respectively. Moreover, the same analysis was performed based on the BEST dataset as well. The results of the leading modes and corresponding PCs are shown in Fig. 18. Although there are some visible differences, the spatial distributions features of EOF1 and EOF2 of interannual variation of NA EHE frequency in GHCND-CMA are very similar to those in BEST. The PC1 and PC2 in GHCND-CMA are correlated to that in BEST with the correlation coefficients of 0.90 and 0.86 , respectively (all significant at the $99 \%$ confidence level). The consistent EOF results obtained in BEST indicate that the dominant modes of the NA EHE frequency derived from the GHCND-CMA dataset are robust and do not depend on the data source.
In this study, the EOF analysis is performed over the region of $40^{\circ}-75^{\circ} \mathrm{N}, 60^{\circ}-140^{\circ} \mathrm{E}$. To further test the sensitivity of EOF analysis to the study area, a similar EOF analysis is further performed for the EHE frequency over a larger area $\left(30^{\circ}-75^{\circ} \mathrm{N}, 50^{\circ}-140^{\circ} \mathrm{E}\right)$. The result shows that although there are some visible differences, the two leading EOF modes of the EHE frequency over a larger area are generally consistent with that shown in Fig. 2 (figure not shown), which indicates that the two leading EOF modes of NA EHE frequency could be insensitive to the selection of study area.

The local mechanisms for the interannual variation in the NA EHE frequency are investigated in this study. More EHEs are always associated with local anomalous highs, which contribute to less middle and low cloud cover and more solar radiation reaching and heating the ground surface. The warmer ground surface further increases the temperature of the overlying atmosphere through longwave radiation and sensible heat flux. The warm temperature advection in the lower troposphere also favors the higher EHE frequency. Meanwhile, lessened soil moisture favors the increase of near-surface air temperatures. 

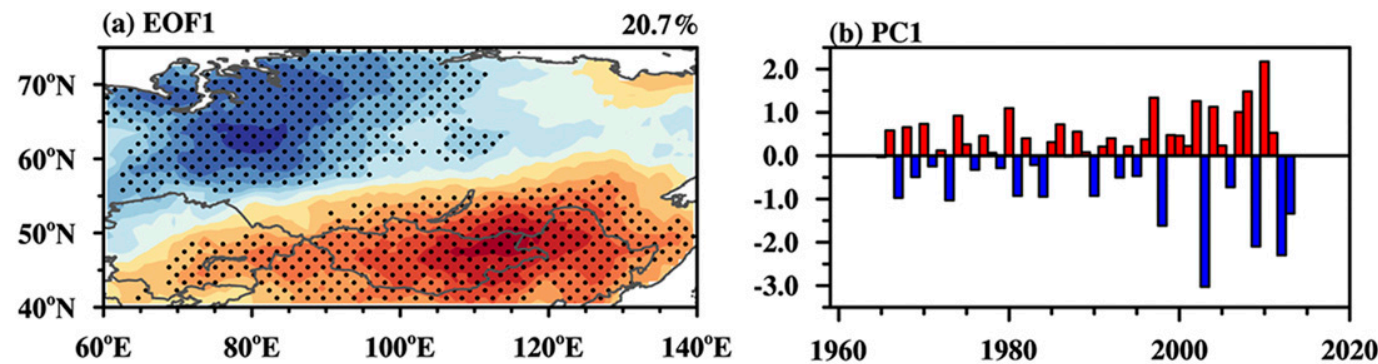

(c) EOF2

$13.6 \%$
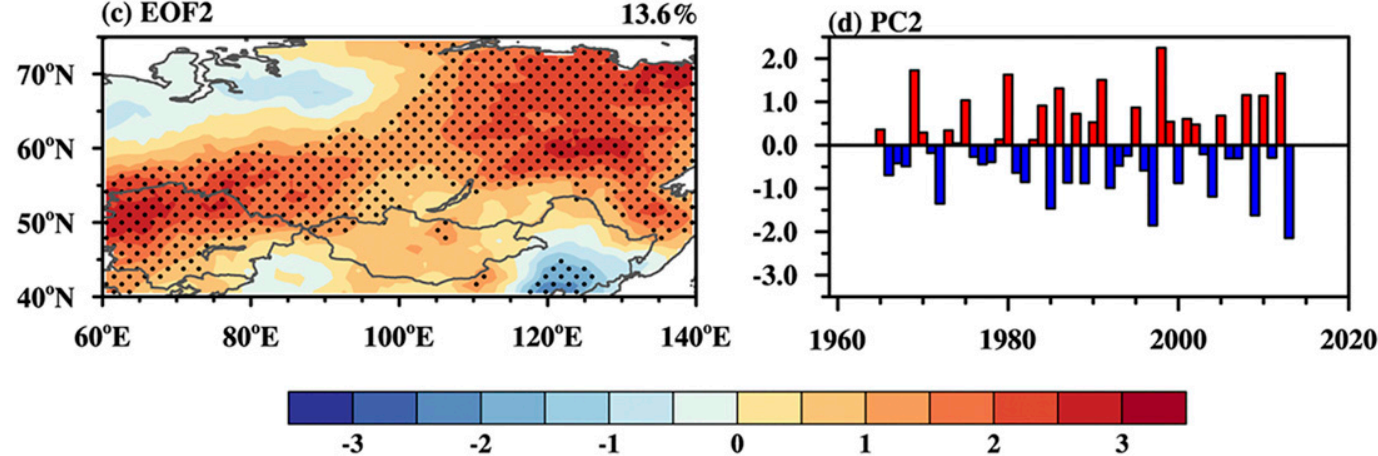

FIG. 18. As in Fig. 2, but the EHEs are defined based on the data from BEST.

Atmospheric teleconnections and oceanic forcings play important roles in the formation of the two leading modes of the NA EHE frequency. The EHE-related local anomalous highs observed in EOF1 and EOF2 are modulated by the POL pattern and $\mathrm{NAO}$, respectively. In addition to the wave train located in the middle and high latitudes, the EOF2 mode is also influenced by the well-known PJ/EAP pattern. Previous studies have explored the influences of the NAO (e.g., Sun 2012; Deng et al. 2019; Zhu et al. 2020a) and EAP pattern (Lee and Lee 2016; Zhu et al. 2020a) on the EHE frequency over the East Asia. The results obtained in this paper reflect that the NAO and EAP pattern can also influence far northward on the variation in NA EHE frequency.

Furthermore, the interannual variation in the EHE frequency was fitted based on the three atmospheric teleconnection indices. The results show good performance over most areas of NA. From the perspective of the regional average, the fitted results can explain $33.8 \%$ of the total interannual variation in the NA EHE frequency.
The two leading EOF modes are further shown to be correlated to anomalous SST patterns over the North Atlantic Ocean, the Mediterranean Sea, and around the Maritime Continent. Under the joint action of anomalous SST anomalies in the western North Atlantic Ocean and western Mediterranean Sea regions, the North Atlantic-Eurasia part of the POL pattern is strengthened and consequently impacts the EOF1 mode. The NAT SST pattern over the North Atlantic Ocean has been revealed to couple with the NAO pattern (e.g., Czaja and Frankignoul 2002; Peng et al. 2003; Pan 2005; Chen et al. 2020). The results in this paper further confirm that the appearance of the NAT SST pattern is conducive to the enhancement of the NAO and explore that the NAT SST pattern stimulate a PC2-like wave train from midto high latitudes to form the EOF2 pattern over NA. An anomalous SST pattern and convection around the Maritime Continent can be connected to the dipole pattern of NA EHE frequency over eastern NA through the PJ/EAP pattern. The (a) EHE_index

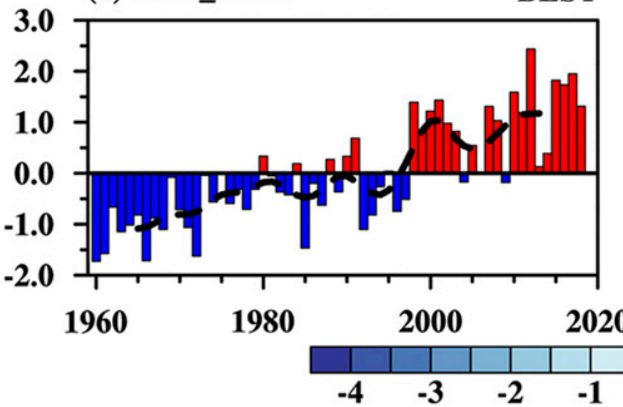

(b) EHE_Frequency

Reg to EHE_index

FIG. 19. As in Fig. 14, but the EHEs are defined based on the data from BEST. 
aforementioned connections between the SST patterns and the atmospheric teleconnections are further confirmed by the AMIP experiment results.

From the perspective of interdecadal variation, a significant interdecadal increase in the EHE frequency occurs over most areas of NA around the mid-1990s. To confirm this result, the same analysis is further performed based on the BEST dataset. As shown in Fig. 19a, the EHE index from the BEST dataset also shows an interdecadal change around the mid1990s, and the EHE indices from the GHCND-CMA and BEST are well correlated, with a coefficient of 0.95 (significant at the $99.9 \%$ confidence level). Similar to that observed in the GHCND-CMA, most areas of NA experienced an interdecadal increase around the mid-1990s in the BEST (Fig. 19b). The consistent results obtained from the two datasets demonstrate that the observed interdecadal increase in the EHE frequency is robust.

The results in this paper further reveal that the favorable conditions for the interdecadal variation of NA EHE frequency are similar to that for interannual variation except for the lesser contribution from temperature advection. Further analysis shows that the observed interdecadal increase in the EHE frequency around the mid-1990s is associated with an anomalous high pressure system over Mongolia and the phase shift of the AMO. In addition, the increase in the EHE frequency around the mid1990s could also be related to the global warming trend.

In this study, we emphasize the influence of atmospheric circulations and oceanic forcings. Along with the global warming, the Artic sea ice is melting significantly. Previous studies have indicated the impact of anomalous Arctic sea ice on summer drought over northeastern Asia, heat waves over East Asia and Europe, and summer precipitation over China (e.g., Wang and He 2015; Li et al. 2018; Zhang et al. 2018; Wu and Francis 2019; Zhang et al. 2020). Is there any connection between the Arctic sea ice and NA EHE? This question is out the scope of this study. Therefore, in the future, the connection between the NA EHE frequency and Arctic sea ice should be systematically investigated, which could provide a more comprehensive understanding of NA EHE variation.

Acknowledgments. This study was supported by the National Natural Science Foundation of China (Grants 41991281 and 41825010).

\section{REFERENCES}

Alexander, L. V., 2011: Extreme heat rooted in dry soils. Nat. Geosci., 4, 12-13, https://doi.org/10.1038/ngeo1045.

— mate extremes of temperature and precipitation. J. Geophys. Res., 111, D05109, https://doi.org/10.1029/2005JD006290.

Balling, R. C., and G. B. Goodrich, 2011: Interannual variations in the local spatial autocorrelation of tropospheric temperatures. Theor. Appl. Climatol., 103, 451-457, https://doi.org/10.1007/ s00704-010-0313-8.

Barnston, A. G., and R. E. Livezey, 1987: Classification, seasonality and persistence of low-frequency atmospheric circulation patterns. Mon. Wea. Rev., 115, 1083-1126, https://doi.org/10.1175/ 1520-0493(1987)115<1083:CSAPOL >2.0.CO;2.
Barriopedro, D., E. M. Fischer, J. Luterbacher, R. M. Trigo, and R. García-Herrera, 2011: The hot summer of 2010: Redrawing the temperature record map of Europe. Science, 332, 220-224, https://doi.org/10.1126/science.1201224.

Black, E., M. Blackburn, G. Harrison, B. Hoskins, and J. Methven, 2004: Factors contributing to the summer 2003 European heatwave. Weather, 59, 217-223, https://doi.org/10.1256/wea.74.04.

Brown, S. J., J. Caesar, and C. A. T. Ferro, 2008: Global changes in extreme daily temperature since 1950. J. Geophys. Res., 113, D05115, https://doi.org/10.1029/2006JD008091.

Budikova, D., T. W. Ford, and T. J. Ballinger, 2019: United States heat wave frequency and Arctic Ocean marginal sea ice variability. J. Geophys. Res. Atmos., 124, 6247-6264, https://doi.org/ 10.1029/2018JD029365.

Chen, H., and J. Sun, 2018: Projected changes in climate extremes in China in a $1.5^{\circ} \mathrm{C}$ warmer world. Int. J. Climatol., 38, 36073617, https://doi.org/10.1002/joc.5521.

Chen, R., Z. Wen, and R. Lu, 2018: Large-scale circulation anomalies and intraseasonal oscillations associated with longlived extreme heat events in South China. J. Climate, 31, 213232, https://doi.org/10.1175/JCLI-D-17-0232.1.

Chen, S., R. Wu, and W. Chen, 2020: Strengthened connection between springtime North Atlantic Oscillation and North Atlantic tripole SST pattern since the late 1980s. J. Climate, 33, 2007-2022, https://doi.org/10.1175/JCLI-D-19-0628.1.

Ciais, P., and Coauthors, 2005: Europe-wide reduction in primary productivity caused by the heat and drought in 2003. Nature, 437, 529-533, https://doi.org/10.1038/nature03972.

Claud, C., B. Duchiron, and P. Terray, 2007: Associations between large-scale atmospheric circulation and polar low developments over the North Atlantic during winter. J. Geophys. Res., 112, D12101, https://doi.org/10.1029/2006JD008251.

Czaja, A., and C. Frankignoul, 2002: Observed impact of Atlantic SST anomalies on the North Atlantic Oscillation. J. Climate, 15, 606-623, https://doi.org/10.1175/1520-0442(2002)015<0606: OIOASA $>2.0 . \mathrm{CO} ; 2$.

Deng, K., S. Yang, M. Ting, P. Zhao, and Z. Wang, 2019: Dominant modes of China summer heat waves driven by global sea surface temperature and atmospheric internal variability. J. Climate, 32, 3761-3775, https://doi.org/10.1175/JCLI-D-18-0256.1.

Ding, Q., and B. Wang, 2005: Circumglobal teleconnection in the Northern Hemisphere summer. J. Climate, 18, 3483-3505, https://doi.org/10.1175/JCLI3473.1.

Ding, T., H. Gao, and W. Li, 2018: Extreme high-temperature event in southern China in 2016 and the possible role of crossequatorial flows. Int. J. Climatol., 38, 3579-3594, https://doi.org/ 10.1002/joc.5518.

Dong, B., R. T. Sutton, W. Chen, X. Liu, R. Lu, and Y. Sun, 2016: Abrupt summer warming and changes in temperature extremes over Northeast Asia since the mid-1990s: Drivers and physical processes. Adv. Atmos. Sci., 33, 1005-1023, https:// doi.org/10.1007/s00376-016-5247-3.

Duchon, C. E., 1979: Lanczos filtering in one and two dimensions. J. Appl. Meteor. Climatol., 18, 1016-1022, https://doi.org/ 10.1175/1520-0450(1979)018<1016:LFIOAT>2.0.CO;2.

Easterling, D. R., G. A. Meehl, C. Parmesan, S. A. Changnon, T. R. Karl, and L. O. Mearns, 2000: Climate extremes: Observations, modeling, and impacts. Science, 289, 20682074, https://doi.org/10.1126/science.289.5487.2068.

Enfield, D. B., A. M. Mestas-Nunez, and P. J. Trimble, 2001: The Atlantic Multidecadal Oscillation and its relationship to rainfall and river flows in the continental U.S. Geophys. Res. Lett., 28, 2077-2080, https://doi.org/10.1029/2000GL012745. 
Enomoto, T., 2004: Interannual variability of the Bonin high associated with the propagation of Rossby waves along the Asian jet. J. Meteor. Soc. Japan, 82, 1019-1034, https://doi.org/ 10.2151/jmsj.2004.1019.

Eyring, V., S. Bony, G. A. Meehl, C. A. Senior, B. Stevens, R. J. Stouffer, and K. E. Taylor, 2016: Overview of the Coupled Model Intercomparison Project Phase 6 (CMIP6) experimental design and organization. Geosci. Model Dev., 9, 1937-1958, https://doi.org/10.5194/gmd-9-1937-2016.

Feldstein, S. B., 2003: The dynamics of NAO teleconnection pattern growth and decay. Quart. J. Roy. Meteor. Soc., 129, 901-924, https://doi.org/10.1256/qj.02.76.

Fischer, E. M., and C. Schär, 2010: Consistent geographical patterns of changes in high-impact European heatwaves. Nat. Geosci., 3, 398-403, https://doi.org/10.1038/ngeo866.

—, S. I. Seneviratne, P. L. Vidale, D. Lüthi, and C. Schär, 2007: Soil moisture-atmosphere interactions during the 2003 European summer heat wave. J. Climate, 20, 5081-5099, https://oi.org/ 10.1175/JCLI4288.1.

Fischer, T., M. Gemmer, L. Liu, and B. Su, 2012: Change-points in climate extremes in the Zhujiang River Basin, South China, 1961-2007. Climatic Change, 110, 783-799, https://doi.org/ 10.1007/s10584-011-0123-8.

Gao, M., J. Yang, B. Wang, S. Zhou, D. Gong, and S. Kim, 2018: How are heat waves over Yangtze River valley associated with atmospheric quasi-biweekly oscillation? Climate Dyn., 51, 4421-4437, https://doi.org/10.1007/s00382-017-3526-z.

Gao, T., J. Y. Yu, and H. Paek, 2017: Impacts of four northernhemisphere teleconnection patterns on atmospheric circulations over Eurasia and the Pacific. Theor. Appl. Climatol., 129, 815-831, https://doi.org/10.1007/s00704-016-1801-2.

Gillett, N. P., D. A. Stone, P. A. Stott, T. Nozawa, A. Y. Karpechko, G. C. Hegerl, M. F. Wehner, and P. D. Jones, 2008: Attribution of polar warming to human influence. Nat. Geosci., 1, 750-754, https://doi.org/10.1038/ngeo338.

Grossmann, I., and P. J. Klotzbach, 2009: A review of North Atlantic modes of natural variability and their driving mechanisms. J. Geophys. Res., 114, D24107, https://doi.org/10.1029/2009JD012728.

Harpaz, T., B. Ziv, H. Saaroni, and E. Beja, 2014: Extreme summer temperatures in the East Mediterranean-dynamical analysis. Int. J. Climatol., 34, 849-862, https://doi.org/10.1002/joc.3727.

Hong, H., J. Sun, and H. Wang, 2020: Interdecadal variation in the frequency of extreme hot events in Northeast China and the possible mechanism. Atmos. Res., 244, 105065, https://doi.org/ 10.1016/j.atmosres.2020.105065.

Horton, R. M., J. S. Mankin, C. Lesk, E. Coffel, and C. Raymond, 2016: A review of recent advances in research on extreme heat events. Curr. Climate Change Rep., 2, 242-259, https://doi.org/ 10.1007/s40641-016-0042-x.

$\mathrm{Hu}, \mathrm{L}$., and G. Huang, 2020: The changes of high-temperature extremes and their links with atmospheric circulation over the Northern Hemisphere. Theor. Appl. Climatol., 139, 261-274, https://doi.org/10.1007/s00704-019-02970-1.

Huang, D., Y. Qian, and J. Zhu, 2010: Trends of temperature extremes in China and their relationship with global temperature anomalies. Adv. Atmos. Sci., 27, 937-946, https://doi.org/ 10.1007/s00376-009-9085-4.

Huang, G., and Z. Yan, 1999: The East Asian summer monsoon circulation anomaly index and its interannual variations. Chinese Sci. Bull., 44, 1325-1329, https://doi.org/10.1007/BF02885855.

Huang, R., and F. Sun, 1992: Impacts of the tropical western Pacific on the East Asian summer monsoon. J. Meteor. Soc. Japan, 70, 243-256, https://doi.org/10.2151/jmsj1965.70.1B_243.
Hurrell, J. W., Y. Kushnir, G. Ottersen, and M. Visbeck, 2003: An overview of the North Atlantic Oscillation. The North Atlantic Oscillation: Climatic Significance and Environmental Impact, Geophys. Monogr., Vol. 134, Amer. Geophys. Union, 1-36.

IPCC, 2013: Climate Change 2013: The Physical Science Basis. Cambridge University Press, 1535 pp., https://doi.org/10.1017/ CBO9781107415324.

Kobayashi, S., and Coauthors, 2015: The JRA-55 reanalysis: General specifications and basic characteristics. J. Meteor. Soc. Japan, 93, 5-48, https://doi.org/10.2151/jmsj.2015-001.

Kosaka, Y., and H. Nakamura, 2006: Structure and dynamics of the summertime Pacific-Japan teleconnection pattern. Quart. J. Roy. Meteor. Soc., 132, 2009-2030, https://doi.org/10.1256/ qj.05.204.

—, and - 2010: Mechanisms of meridional teleconnection observed between a summer monsoon system and a subtropical anticyclone. Part I: The Pacific-Japan pattern. J. Climate, 23, 5085-5108, https://doi.org/10.1175/2010JCLI3413.1.

,,-- M. Watanabe, and M. Kimoto, 2009: Analysis on the dynamics of a wave-like teleconnection pattern along the summertime Asian jet based on a reanalysis dataset and climate model simulations. J. Meteor. Soc. Japan, 87, 561-580, https://doi.org/10.2151/jmsj.87.561.

Lee, W. S., and M. I. Lee, 2016: Interannual variability of heat waves in South Korea and their connection with large-scale atmospheric circulation patterns. Int. J. Climatol., 36, 48154830, https://doi.org/10.1002/joc.4671.

Li, H., H. Chen, H. Wang, J. Sun, and J. Ma, 2018: Can Barents Sea ice decline in spring enhance summer hot drought events over northeastern China? J. Climate, 31, 4705-4725, https://doi.org/ 10.1175/JCLI-D-17-0429.1.

— S. He, Y. Gao, H. Chen, and H. Wang, 2020: North Atlantic modulation of interdecadal variations in hot drought events over northeastern China. J. Climate, 33, 4315-4332, https:// doi.org/10.1175/JCLI-D-19-0440.1.

Li, R., and J. Sun, 2018: Interdecadal variability of the large-scale extreme hot event frequency over the middle and lower reaches of the Yangtze River basin and its related atmospheric patterns. Atmos. Oceanic Sci. Lett., 11, 63-70, https://doi.org/ 10.1080/16742834.2017.1335580.

Li, S., and G. T. Bates, 2007: Influence of the Atlantic multidecadal oscillation on the winter climate of East China. Adv. Atmos. Sci., 24, 126-135, https://doi.org/10.1007/s00376-007-0126-6.

Lorenz, E. N., 1956: Empirical orthogonal functions and statistical weather prediction. MIT Department of Meteorology Statistical Forecasting Project Scientific Rep. 1, 49 pp.

Lu, R., and Z. Lin, 2009: Role of subtropical precipitation anomalies in maintaining the summertime meridional teleconnection over the western North Pacific and East Asia. J. Climate, 22, 2058-2072, https://doi.org/10.1175/2008JCLI2444.1.

, and R. Chen, 2016: A review of recent studies on extreme heat in China. Atmos. Oceanic Sci. Lett., 9, 114-121, https:// doi.org/10.1080/16742834.2016.1133071.

Luo, M., and N.-C. Lau, 2017: Heat waves in southern China: Synoptic behavior, long-term change, and urbanization effects. J. Climate, 30, 703-720, https://doi.org/10.1175/JCLI-D16-0269.1.

- , and 2020: Summer heat extremes in northern continents linked to developing ENSO events. Environ. Res. Lett., 15, 074042, https://doi.org/10.1088/1748-9326/ab7d07.

McCarthy, M. P., M. J. Best, and R. A. Betts, 2010: Climate change in cities due to global warming and urban effects. Geophys. Res. Lett., 37, L09705, https://doi.org/10.1029/2010GL042845. 
Meehl, G. A., and C. Tebaldi, 2004: More intense, more frequent, and longer lasting heat waves in the 21 st century. Science, $\mathbf{3 0 5}$, 994-997, https://doi.org/10.1126/science.1098704.

Menne, M. J., I. Durre, R. S. Vose, B. E. Gleason, and T. G. Houston, 2012: An overview of the Global Historical Climatology Network-Daily database. J. Atmos. Oceanic Technol., 29, 897-910, https://doi.org/10.1175/JTECH-D-11-00103.1.

Miralles, D. G., A. J. Teuling, C. C. van Heerwaarden, and J. V. G. de Arellano, 2014: Mega-heatwave temperatures due to combined soil desiccation and atmospheric heat accumulation. Nat. Geosci., 7, 345-349, https://doi.org/10.1038/ngeo2141.

Morak, S., G. C. Hegerl, and N. Christidis, 2013: Detectable changes in the frequency of temperature extremes. J. Climate, 26, 1561-1574, https://doi.org/10.1175/JCLI-D-11-00678.1.

Nakamura, H., and T. Fukamachi, 2004: Evolution and dynamics of summertime blocking over the Far East and the associated surface Okhotsk high. Quart. J. Roy. Meteor. Soc., 130, 12131233, https://doi.org/10.1256/qj.03.101.

Nitta, T., 1987: Convective activities in the tropical western Pacific and their impact on the Northern Hemisphere summer circulation. J. Meteor. Soc. Japan, 65, 373-390, https://doi.org/ 10.2151/jmsj1965.65.3_373.

North, G. R., T. L. Bell, R. F. Cahalan, and F. J. Moeng, 1982: Sampling errors in the estimation of empirical orthogonal functions. Mon. Wea. Rev., 110, 699-706, https://doi.org/ 10.1175/1520-0493(1982)110<0699:SEITEO>2.0.CO;2.

Orlowsky, B., and S. I. Seneviratne, 2012: Global changes in extreme events: Regional and seasonal dimension. Climatic Change, 110, 669-696, https://doi.org/10.1007/s10584-011-0122-9.

Pan, L. L., 2005: Observed positive feedback between the NAO and the North Atlantic SSTA tripole. Geophys. Res. Lett., 32, L06707, https://doi.org/10.1029/2005GL022427.

Peng, S., W. A. Robinson, and S. Li, 2003: Mechanisms for the NAO responses to the North Atlantic SST tripole. J. Climate, 16, 1987-2004, https://doi.org/10.1175/1520-0442(2003)016<1987: MFTNRT $>2.0 . \mathrm{CO} ; 2$.

Perkins, S. E., 2015: A review on the scientific understanding of heatwaves-Their measurement, driving mechanisms, and changes at the global scale. Atmos. Res., 164, 242-267, https:// doi.org/10.1016/j.atmosres.2015.05.014.

Quenouille, M. H., 1952: Associated Measurements. Academic Press, 242 pp.

Rayner, N. A., D. E. Parker, E. B. Horton, C. K. Folland, L. V. Alexander, D. P. Rowell, E. C. Kent, and A. Kaplan, 2003: Global analyses of sea surface temperature, sea ice, and night marine air temperature since the late nineteenth century. J. Geophys. Res., 108, 4407, https://doi.org/10.1029/2002JD002670.

Rohde, R., and Coauthors, 2013: Berkeley Earth temperature averaging process. Geoinfo. Geostat., 1 (2), https://doi.org/ 10.4172/2327-4581.1000103.

Sanderson, M. G., D. L. Hemming, and R. A. Betts, 2011: Regional temperature and precipitation changes under high-end $\left(\geq 4^{\circ} \mathrm{C}\right)$ global warming. Philos. Trans. Roy. Soc., 369A, 85-98, https:// doi.org/10.1098/rsta.2010.0283.

Sardeshmukh, P. D., and B. J. Hoskins, 1988: The generation of global rotational flow by steady idealized tropical divergence. J. Atmos. Sci., 45, 1228-1251, https://doi.org/10.1175/15200469(1988)045<1228:TGOGRF>2.0.CO;2.

Schär, C., and G. Jendritzky, 2004: Hot news from summer 2003. Nature, 432, 559-560, https://doi.org/10.1038/432559a.

Schlesinger, M., and N. Ramankutty, 1994: An oscillation in the global climate system of period 65-70 years. Nature, $\mathbf{3 6 7}, 723-$ 726, https://doi.org/10.1038/367723a0.
Shaposhnikov, D., and Coauthors, 2014: Mortality related to air pollution with the Moscow heat wave and wildfire of 2010. Epidemiology, 25, 359-364, https://doi.org/10.1097/EDE.0000000000000090.

Shi, N., Y. Wang, X. Wang, and P. Tian, 2019: Interdecadal variations in the frequency of persistent hot events in boreal summer over midlatitude Eurasia. J. Climate, 32, 5161-5177, https://doi.org/10.1175/JCLI-D-18-0706.1.

Si, D., and Y. Ding, 2016: Oceanic forcings of the interdecadal variability in East Asian summer rainfall. J. Climate, 29, 76337649, https://doi.org/10.1175/JCLI-D-15-0792.1.

Sun, C., J. Li, and S. Zhao, 2015: Remote influence of Atlantic multidecadal variability on Siberian warm season precipitation. Sci. Rep., 5, 16853, https://doi.org/10.1038/srep16853.

Sun, J., 2012: Possible impact of the summer North Atlantic Oscillation on extreme hot events in China. Atmos. Oceanic Sci. Lett., 5, 231-234, https://doi.org/10.1080/16742834.2012.11446996.

_, 2014 : Record-breaking SST over mid-North Atlantic and extreme high temperature over the Jianghuai-Jiangnan region of China in 2013. Chin. Sci. Bull., 59, 3465-3470, https:// doi.org/10.1007/s11434-014-0425-0.

_- H. Wang, and W. Yuan, 2011: Decadal variability of the extreme hot event in China and its association with atmospheric circulations (in Chinese). Climate Environ. Res., 16, 199-208.

Sun, Y., X. Zhang, F. W. Zwiers, L. Song, H. Wang, H. Ting, H. Yin, and G. Ren, 2014: Rapid increase in the risk of extreme summer heat in Eastern China. Nat. Climate Change, 4 , 1082-1085, https://doi.org/10.1038/nclimate2410.

Tachibana, Y., T. Iwamoto, M. Ogi, and Y. Watanabe, 2004: Abnormal meridional temperature gradient and its relation to the Okhotsk high. J. Roy. Meteor. Soc., 82, 1399-1415, https:// doi.org/10.2151/jmsj.2004.1399.

Takaya, K., and H. Nakamura, 2001: A formulation of a phaseindependent wave-activity flux for stationary and migratory quasigeostrophic eddies on a zonally varying basic flow. J. Atmos. Sci., 58, 608-627, https://doi.org/10.1175/15200469(2001)058<0608:AFOAPI > 2.0.CO;2.

Tebaldi, C., K. Hayhoe, J. M. Arblaster, and G. A. Meehl, 2006: Going to the extremes. Climatic Change, 79, 185-211, https:// doi.org/10.1007/s10584-006-9051-4.

Thirumalai, K., P. N. DiNezio, Y. Okumura, and C. Deser, 2017: Extreme temperatures in Southeast Asia caused by El Niño and worsened by global warming. Nat. Commun., 8, 15531, https://doi.org/10.1038/ncomms15531.

Walker, G. T., and E. W. Bliss, 1932: World weather V. Mem. Roy. Meteor. Soc., 4, 53-84.

Wallace, J. M., and D. S. Gutzler, 1981: Teleconnections in the geopotential height field during the Northern Hemisphere winter. Mon. Wea. Rev., 109, 784-812, https://doi.org/10.1175/ 1520-0493(1981)109<0784:TITGHF>2.0.CO;2.

Wang, H., and S. He, 2015: The north China/northeastern Asia severe summer drought in 2014. J. Climate, 28, 6667-6681, https://doi.org/10.1175/JCLI-D-15-0202.1.

Wang, W., W. Zhou, X. Wang, S. K. Fong, and K. C. Leong, 2013: Summer high temperature extremes in Southeast China associated with the East Asian jet stream and circumglobal teleconnection. J. Geophys. Res. Atmos., 118, 8306-8319, https://doi.org/10.1002/jgrd.50633.

,-- , and D. Chen, 2014: Summer high temperature extremes in southeast China: Bonding with the El Niño-Southern Oscillation and East Asian summer monsoon coupled system. J. Climate, 27, 4122-4138, https://doi.org/10.1175/JCLID-13-00545.1. 
- — - X. Li, X. Wang, and D. Wang, 2016: Synoptic-scale characteristics and atmospheric controls of summer heat waves in China. Climate Dyn., 46, 2923-2941, https://doi.org/ 10.1007/s00382-015-2741-8.

Wu, B., and J. A. Francis, 2019: Summer Arctic cold anomaly dynamically linked to East Asian heat waves. J. Climate, 32, 1137-1150, https://doi.org/10.1175/JCLI-D-18-0370.1.

Xu, P., L. Wang, and W. Chen, 2019: The British-Baikal corridor: A teleconnection pattern along the summertime polar front jet over Eurasia. J. Climate, 32, 877-896, https://doi.org/10.1175/ JCLI-D-18-0343.1.

Yang, H., and C. Li, 2005: Diagnostic study of serious high temperature over South China in 2003 summer (in Chinese). Climate Environ. Res., 10, 80-85.

Yin, Z., H. Wang, and X. Liu, 2014: A comparative study on precipitation climatology and interannual variability in the lower midlatitude East Asia and Central Asia. J. Climate, 27, 78307848, https://doi.org/10.1175/JCLI-D-14-00052.1.

Yu, S., Z. Yan, N. Freychet, and Z. Li, 2020: Trends in summer heatwaves in central Asia from 1917 to 2016: Association with large-scale atmospheric circulation patterns. Int. J. Climatol., 40, 115-127, https://doi.org/10.1002/joc.6197.

Zampieri, M., F. D'Andrea, R. Vautard, P. Ciais, N. de NobletDucoudré, and P. Yiou, 2009: Hot European summers and the role of soil moisture in the propagation of Mediterranean drought. J. Climate, 22, 4747-4758, https://doi.org/10.1175/ 2009JCLI2568.1.

Zhai, P., and X. Pan, 2003: Trends in temperature extremes during 1951-1999 in China. Geophys. Res. Lett., 30, 1913, https:// doi.org/10.1029/2003GL018004.

Zhang, R., C. Sun, and W. Li, 2018: Relationship between the interannual variations of Arctic sea ice and summer Eurasian teleconnection and associated influence on summer precipitation over China (in Chinese). Chin. J. Geophys., 61, 91-105.

,$- \ldots$, J. Zhu, R. Zhang, and W. Li, 2020: Increased European heat waves in recent decades in response to shrinking Arctic sea ice and Eurasian snow cover. npj Climate Atmos. Sci., 3 (7), https://doi.org/10.1038/s41612-020-0110-8.

Zhu, B., B. Sun, and H. Wang, 2020a: Dominant modes of interannual variability of extreme high-temperature events in eastern China during summer and associated mechanisms. Int. J. Climatol., 40, 841-857, https://doi.org/10.1002/joc.6242.

,,$-- \mathrm{H}$. Li, and H. Wang, 2020b: Interdecadal variations in extreme high-temperature events over southern China in the early 2000 s and the influence of the Pacific decadal oscillation. Atmosphere, 11, 829, https://doi.org/10.3390/ atmos11080829.

Ziv, B., H. Saaroni, and P. Alpert, 2004: The factors governing the summer regime of the eastern Mediterranean. Int. J. Climatol., 24, 1859-1871, https://doi.org/10.1002/joc.1113. 